This is the final peer-reviewed accepted manuscript of:

Greta Giacobazzi, Matteo Rizzuto, Manuela Zubitur, Agurtzane Mugic², Daniele Caretti and Alejandro J. Müller*

Crystallization kinetics as a sensitive tool to detect degradation in poly(lactide)/poly(e-caprolactone)/ PCL-co-PC copolymers blends

Polymer Degradation and Stability 168 (2019) 108939

The final published version is available online at: 10.1016/i.polymdegradstab.2019.108939

Rights / License:

The terms and conditions for the reuse of this version of the manuscript are specified in the publishing policy. For all terms of use and more information see the publisher's website.

This item was downloaded from IRIS Università di Bologna (https://cris.unibo.it/)

When citing, please refer to the published version. 


\section{Crystallization kinetics as a sensitive tool to detect degradation in poly(lactide)/poly(\&-caprolactone)/ PCL-co-PC copolymers blends}

Greta Giacobazzi ${ }^{1,2}$, Matteo Rizzuto ${ }^{1,2}$, Manuela Zubitur ${ }^{3}$, Agurtzane Mugica ${ }^{2}$, Daniele Caretti ${ }^{1}$ and Alejandro J. Müller ${ }^{2,4 *}$

${ }^{1}$ Dipartimento di Chimica Industriale “Toso Montanari”, Università di Bologna (UNIBO), Viale del Risorgimento ${ }^{\circ}$ 4, 40136 Bologna, Italy.

${ }^{2}$ POLYMAT and Polymer Science and Technology Department, Faculty of Chemistry, University of the Basque Country UPV/EHU, Paseo Manuel de Lardizabal 3, 20018 Donostia-San Sebastián, Spain.

${ }^{3}$ Chemical and Environmental Engineering Department, Polytechnic School, University of the Basque Country UPV/EHU, 20018 Donostia-San Sebastián, Spain

${ }^{4}$ IKERBASQUE, Basque Foundation for Science, Bilbao, Spain.

*Corresponding author

Email: alejandrojesus.muller@ehu.es

This item was downloaded from IRIS Università di Bologna (https://cris.unibo.it/)

When citing, please refer to the published version. 


\section{ABSTRACT}

Poly(lactide)/poly(e-caprolactone) blends (PLA/PCL) with composition 80/20 (w/w\%) are immiscible but biodegradable and therefore often studied in the literature. We have prepared 80/20 PLA/PCL blends with and without poly( $\varepsilon$-caprolactone)-co-poly(carbonate) copolymers (block and random). The blends were prepared both by melt extrusion and by solution blending. The concentration of PCL-co-PC copolymers added to the blends was $2 \mathrm{wt} \%$. Compression molded sheets and solvent cast films were evaluated by GPC (Gel Permeation Chromatography), TGA (Thermogravimetric Analysis), SEM (Scanning Electron Microscopy), PLOM (Polarized Light Optical Microscopy) and DSC (Differential Scanning Calorimetry). Copolymer addition causes a reduction of molecular weight in melt mixed blends. In particular, the random copolymer (PCL-ranPC) causes the highest molecular weight reduction, since it has lower thermal stability, as shown by TGA. PLOM experiments show that these degraded PLA chains in melt-mixed blends can nucleate and grow faster than similar but undegraded PLA chains in solution-mixed blends. As a result, the PLA phase within melt mixed blends containing PCL-co-PC copolymers shows a higher tendency to crystallize during both isothermal and non-isothermal DSC experiments. Upon molecular weight reduction in melt mixed blends containing copolymers, PLA chains have a higher mobility resulting in faster diffusion towards the growing crystal front. Our results show crystallization kinetic measurements, performed by PLOM or DSC, are useful tools to qualitatively detect molecular weight changes produced by degradation of PLA chains, when the molecular weight reduction is not large enough to decrease $T_{m}$ values.

Keywords: poly(lactide)-poly( $\varepsilon$-caprolactone) blends, crystallization, solution blending, melt blending

This item was downloaded from IRIS Università di Bologna (https://cris.unibo.it/)

When citing, please refer to the published version. 


\section{Introduction}

Poly(lactide) is one of the most promising substitutes for petroleum-based polymers since it is at the same time bio-based, biocompatible and biodegradable. However, its drawbacks (i.e., slow crystallization rate and brittleness) are limiting its applications and commercial expansion [1,2].

The optical purity of lactic acid is a crucial parameter in PLA crystallization. As the optical purity of LA is lowered, the PLA capacity of crystallization decreases [3]. PLA can develop significant crystallinity when one of the two forms (L or D) is present in a high enough amount (at least more than 96-97\%).

Blending PLA with poly( $\varepsilon$-caprolactone) (PCL) is one possible solution to improve PLA properties. PCL is flexible, biodegradable and biocompatible and thus could potentially toughen PLA without significantly reducing most of its advantageous properties [4].

The crystallization, as other final properties, of a polymer blend depends on the miscibility or immiscibility of both components $[5,6]$. When the blend is miscible, the properties of the single-phase produced, for example, crystallization, depend on the changes of the glass transition and equilibrium melting temperatures as a consequence of blending [7].

PLA and PCL are immiscible over a wide range of temperature, composition and molecular weight, as confirmed by many previous studies where the polymers were mixed in solution [8-11] or in the melt [12-14]. Several strategies of compatibilization for PLA/PCL blends have been reported in the literature to improve the miscibility between the two phases [15]. The addition of block copolymers is an efficient way to compatibilize polymer blends given the relatively low costs involved in comparison with the other methods of compatibilization [16].

Many efforts focus on the compatibilization of PLA/PCL blends through the addition of block copolymers of PLA and PCL [17]. Effective results are usually obtained with copolymers in which

This item was downloaded from IRIS Università di Bologna (https://cris.unibo.it/)

When citing, please refer to the published version. 
one of the two blocks is miscible, but not identical, to one of the blend components. Rizzuto et al. [18] reported a threefold reduction of PCL particle size in 80/20 PLA/PCL blends by using a diblock copolymer of PLA and PC (miscible with PCL phase) with positive effects in PLA properties including acceleration of its crystallization rate. Random copolymers can act as effective compatibilizers since the sequential comonomer units could be regarded as short blocks, miscible with the corresponding blend components. For instance, Choi et al. [19] reported a reduction from 10 $\mu \mathrm{m}$ to $3 \mu \mathrm{m}$ of PCL domains within a 70/30 PLA/PCL upon the addition of 5\% random copolymer PLA-co-PCL. At the same time, upon blending with PCL, PLA crystallization rate can be increased. Xiang et al. [20] prepared PLLA/PCL blends stabilized with PCL- $b$-PLLA with different ratios of CL/LA and molecular weights. They observed an increase of crystallinity with the addition of PCL$b$-PLLA as a consequence of the compatibilization.

If the blends, composed of two semi-crystalline homopolymers, are immiscible with complete phase separation between the two components, the two phases will act independently in terms of crystallization, i.e., each phase will crystallize separately at its own $T_{c}$ range. However, any changes in molecular weight can also affect the crystallization rate. Taken advantage of this behavior, the goal of this paper is to prove the feasibility of using the crystallization kinetic analysis as a tool to detect changes in molecular weight of the PLA phase in PLA/PCL immiscible blends. To reach this goal, the crystallization behavior of the PLA phase within 80/20 PLA/PCL immiscible blends containing

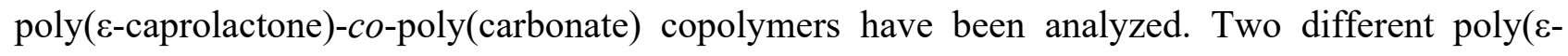
caprolactone)-co-poly(carbonate) based copolymers, one block copolymer, and one statistical copolymer, have been used and blending has been carried out by both melt and solvent mixing. In the case of melt-mixing at the high temperatures and shear rates used in the process, the low molecular weight copolymers may degrade to oligomers and lead to transesterification reactions [21] with

This item was downloaded from IRIS Università di Bologna (https://cris.unibo.it/)

When citing, please refer to the published version. 
thermally unstable PLA chains [22]. And, also, PLA/PCL blends without the addition of copolymers have been analyzed for the sake of comparison.

\section{Experimental}

\subsection{Materials}

Poly(L-lactide) PLA (Ingeo index. 4032D, with 1.2-1.6 \% of D isomer, $M_{w}=200 \mathrm{KDa}$ ) was purchased from NatureWorks ${ }^{\mathrm{TM}}$ and was dried overnight under vacuum at $60{ }^{\circ} \mathrm{C}$ before processing to avoid degradation reactions induced by moisture. Poly( $\varepsilon$-caprolactone) PCL (CAPA $6800 M_{w}=80$ KDa) was purchased from Solvay ${ }^{\mathrm{TM}}$ and was used as received. Poly(carbonate) (PC, TARFLON® IV1900R) was purchased from Idemitsu Chemicals Europe and was used as received. $\varepsilon$-Caprolactone (Sigma-Aldrich-CAS Number. 502-44-3) and tin octanoate (Sigma Aldrich-CAS Number. 301-10-0) were used as received.

Two different random and block copolymers of BPA-Carbonate and $\varepsilon$-Caprolactone were employed in this work. Both copolymers were synthetized by ring opening polymerization using tin (II) octanoate as catalyst and toluene as solvent. The detailed synthesis is described in the Supplementary Material.

\subsection{Blends preparation}

A constant 80/20 PLA/PCL weight ratio was employed. Block and random copolymers were used as compatibilizers by adding $10 \%$ with respect to the PCL phase (i.e., $2 \%$ ). The composition of the final blends is approximately 80/20/2 PLA/PCL/PCL-co-PC. Table 1 reports the exact composition of the prepared blends.

Table 1. Composition of the prepared blends.

This item was downloaded from IRIS Università di Bologna (https://cris.unibo.it/)

When citing, please refer to the published version. 


\begin{tabular}{ccccc}
\hline Sample & $\begin{array}{c}\text { PLA } \\
(\mathrm{w} / \mathrm{w} \%)\end{array}$ & $\begin{array}{c}\text { PCL } \\
(\mathrm{w} / \mathrm{w} \%)\end{array}$ & $\begin{array}{c}\text { PCL- } b \text {-PC } \\
(\mathrm{w} / \mathrm{w} \%)\end{array}$ & $\begin{array}{c}\text { PCL-ran-PC } \\
(\mathrm{w} / \mathrm{w} \%)\end{array}$ \\
\hline PLA (m) & 100 & - & - & - \\
PLA (s) & 100 & - & - & - \\
PCL (m) & - & 100 & - & - \\
PCL (s) & - & 100 & - & - \\
PLA/PCL (m) & 80 & 20 & - & - \\
PLA/PCL (s) & 80 & 20 & - & - \\
PLA/PCL/PCL-b-PC (m) & 79 & 19 & 2 & - \\
PLA/PCL/PCL- $b$-PC (s) & 79 & 19 & 2 & - \\
PLA/PCL/PCL-ran-PC (m) & 79 & 19 & - & 2 \\
PLA/PCL/PCL-ran-PC (s) & 79 & 19 & - & 2 \\
\hline
\end{tabular}

m: melt blended; s: solution blended

The blends were prepared by both solution and melt mixing. The ones prepared by solution mixing have been designated with (s), while the corresponding ones prepared by melt blending have been designated with $(\mathrm{m})$.

In the first case, PLA, PCL and PCL-co-PC copolymers were dissolved in dichloromethane at a concentration of $1 \mathrm{~g} / \mathrm{dL}$ and stirred at room temperature for 3 hours. Films were obtained by casting solutions in Petri dishes (diameter $=5 \mathrm{~cm}$ ), obtaining films that were dried for 24 hours at room temperature and another 24 hours at $60^{\circ} \mathrm{C}$ under vacuum to remove any solvent residue.

In the second case, neat homopolymers and the PCL-co-PC copolymers were melted and blended in a Collin twin-screw extruder (Teachline, L/D ratio 18, screw diameter $25 \mathrm{~mm}$ ). Melt blending was performed at a screw speed of $200 \mathrm{rpm}$, a temperature of $200{ }^{\circ} \mathrm{C}$ with a residence time of approximately 1 minute. The extruded filaments were quenched in a water bath and pelletized. The pellets were dried overnight at $60{ }^{\circ} \mathrm{C}$ under vacuum and were compression molded in a Collin P-200E compression molding machine at $200{ }^{\circ} \mathrm{C}(3$ minutes without pressure followed by 3 minutes at 100 bar). Tensile testing specimens (ASTM D 638 type IV, with $1.84 \mathrm{~mm}$ average thickness) of the blends were obtained.

\subsection{Spectroscopic analysis}

This item was downloaded from IRIS Università di Bologna (https://cris.unibo.it/)

When citing, please refer to the published version. 
Commercial poly(carbonate) and the synthetized copolymers were analyzed by ${ }^{1} \mathrm{H}-\mathrm{NMR}$ experiments. ${ }^{1} \mathrm{H}-\mathrm{NMR}$ spectra have been recorded with a spectrometer Varian Mercury 400 operating at $400 \mathrm{MHz}$ on samples prepared in $\mathrm{CDCl}_{3}$ at the $1.0 \mathrm{wt} \%$. Chemical shifts $(\delta)$ for ${ }^{1} \mathrm{H}$ are given in ppm relative to the known signal of the internal reference (TMS).

\subsection{Molecular weight analysis}

Block and random copolymers and all prepared blends were analyzed by Gel Permeation Chromatography (GPC) using a Waters column with a 717 Autosampler equipped with a double detector, Waters 2487 Dual $\lambda$ Absorbance Detector and Waters 2410 Refractive Index Detector. The column works at $35^{\circ} \mathrm{C}$ using THF as eluent. The samples were prepared at a concentration of about 0.07-0.10 (\%w/V), by using 3.5-5 $\mathrm{mg}$ of the sample dissolved in $5 \mathrm{~mL}$ of THF.

\subsection{Morphological analysis}

The morphology of the blends was investigated by Scanning Electron Microscopy (SEM). Tensile test specimens and films were cryogenically fractured after immersion in liquid nitrogen. Fracture surfaces were observed after gold coating under vacuum, using a Zeiss EP EVO 50 electron microscope equipped with an EDS detector classifiable as Oxford Instrument Inca Energy 350 [ $\mathrm{z}>4$ (Be), resolution 133eV (MnKa@2500cps)].

Micrographs of the most representative inner regions of the specimens were obtained. PCL droplet diameters were measured on at least 100 particles. Number $\left(d_{n}\right)$ and volume $\left(d_{v}\right)$ average diameters and particles size polydispersity $\left(D_{p}\right)$ were calculated by the following equations [23].

$$
d_{n}=\frac{\sum n_{i} d_{i}}{\sum n_{i}}
$$

This item was downloaded from IRIS Università di Bologna (https://cris.unibo.it/) 


$$
d_{v}=\frac{\sum n_{i} d_{i}^{4}}{\sum n_{i} d_{i}^{3}}
$$

$$
D_{p}=\frac{d_{v}}{d_{n}}
$$

where $n_{i}$ is the number of droplets ' $i$ ' of diameter $d_{i}$.

Polarized Light Optical Microscopy (PLOM) was employed to observe the morphology and growth kinetics of PLA spherulites. A red tint plate was inserted in between the polarizers to determine the sign of the spherulites. Micrographs were recorded by a Leica DC 420 camera on film samples with a thickness of approximately $10 \mu \mathrm{m}$, cut from solvent casted films and tensile test specimens. By using a Mettler FP35Hz hot stage, the samples were firstly heated at $200{ }^{\circ} \mathrm{C}$ and held at this temperature for 3 minutes to erase previous thermal history. Finally, they were cooled to the crystallization temperature, and the isothermal spherulitic growth was followed by PLOM.

\subsection{Thermal analysis}

The copolymers and all the blends were analyzed by Thermogravimetric Analysis (TGA) and Differential Scanning Calorimetry (DSC).

The thermal stability of the blends was studied by TGA using a thermobalance TA Instruments, model TGAQ500. All measurements were conducted under a nitrogen atmosphere and using sample masses of approximately $7 \mathrm{mg}$. All the samples were heated from 40 to $600{ }^{\circ} \mathrm{C}$ at a rate of $10^{\circ} \mathrm{C} / \mathrm{min}$.

The thermal behavior of the blends was studied by DSC using a Perkin Elmer DSC Pyris 1 calorimeter equipped with a refrigerated cooling system Intracooler $2 \mathrm{P}$ calibrated with indium and tin. All measurements were performed under a nitrogen atmosphere and using sample masses of

This item was downloaded from IRIS Università di Bologna (https://cris.unibo.it/) 
approximately $5 \mathrm{mg}$. The analyses were conducted with different methods as a function of the experiments.

In non-isothermal analyses, the copolymers were heated from $25{ }^{\circ} \mathrm{C}$ to $200{ }^{\circ} \mathrm{C}$ at the rate of $10{ }^{\circ} \mathrm{C} / \mathrm{min}$ and held at $200{ }^{\circ} \mathrm{C}$ for 3 minutes to erase the thermal history. Then they were cooled at 10 ${ }^{\circ} \mathrm{C} / \mathrm{min}$ until $-80{ }^{\circ} \mathrm{C}$ (to detect the glass transition temperature) and finally heated at $10{ }^{\circ} \mathrm{C} / \mathrm{min}$ to 200 ${ }^{\circ} \mathrm{C}$.

On the other hand, the blends were heated from $25^{\circ} \mathrm{C}$ to $200{ }^{\circ} \mathrm{C}$ at the rate of $10{ }^{\circ} \mathrm{C} / \mathrm{min}$ and held at $200{ }^{\circ} \mathrm{C}$ for 3 minutes to erase the thermal history. Then they were cooled at $10{ }^{\circ} \mathrm{C} / \mathrm{min}$ until $20{ }^{\circ} \mathrm{C}$ and finally heated at $10{ }^{\circ} \mathrm{C} / \min$ to $200{ }^{\circ} \mathrm{C}$.

For isothermal crystallization kinetics, the samples were heated from $25{ }^{\circ} \mathrm{C}$ to $200{ }^{\circ} \mathrm{C}$ at 20 ${ }^{\circ} \mathrm{C} / \mathrm{min}$ and held at this temperature for 3 minutes to erase the thermal history. Then they were cooled at $60{ }^{\circ} \mathrm{C} / \mathrm{min}$ (to avoid PLA crystallization during cooling) to the chosen isothermal crystallization temperature $\left(T_{c}\right)$ and held at this temperature for 30 minutes while recording the evolved crystallization enthalpy.

The isothermal crystallization temperature range was determined by preliminary tests to ensure that no crystallization occurred during the cooling closely following the recommendations given by Lorenzo et al. [24]

\section{Results and discussion}

\subsection{Characterization of PCL-co-PC copolymers}

The synthesis and chain structure characterization by NMR are presented in the Supplementary Information. The resulting weight/weight composition for the block and the random

This item was downloaded from IRIS Università di Bologna (https://cris.unibo.it/)

When citing, please refer to the published version. 
copolymers were 49/51 and 60/40 respectively (see Table S1), while their weight average molecular weights were 18.5 and $14.6 \mathrm{~kg} / \mathrm{mol}$ respectively. As demonstrated by NMR spectra, it is worth noting that in this paper, the copolymer that we have denoted as a "block copolymer", is not a perfect $\mathrm{AB}$ diblock copolymer. It is a copolymer with a blocky structure, as the lengths of PC and PCL are much larger in this copolymer than in a random copolymer of equivalent composition and molecular weight, as explained in the supplementary material. The random copolymer is expected to be miscible in the melt and is also expected not to be able to crystallize.

The thermal behavior of PCL-co-PC copolymers has been investigated by non-isothermal DSC and TGA experiments. In the case of the block copolymer, phase segregation in the melt state could occur depending on the segregation strength given by $\chi N$ (where $\chi$ is the Flory-Huggins interaction parameter between different blocks and $N$ the overall degree of polymerization of the entire block copolymer) [25]. When $\chi N$ is lower than 10, a single-phase melt is usually formed. On the other hand, when $\chi N$ is higher than 10, copolymers segregate in two phases in the melt state.

a)

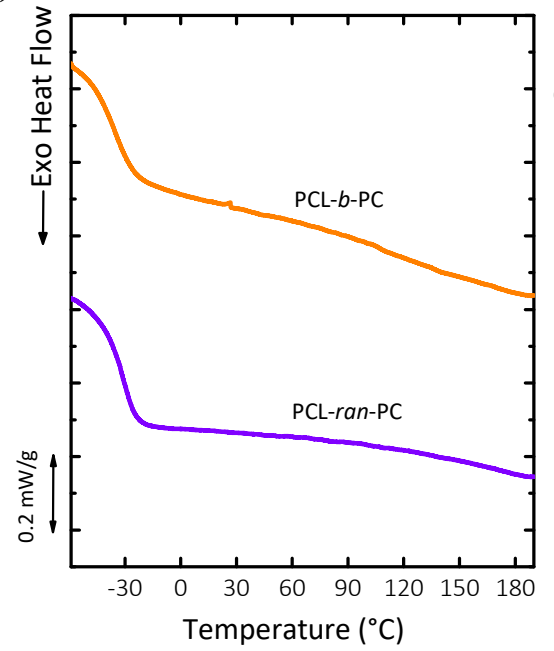

b)

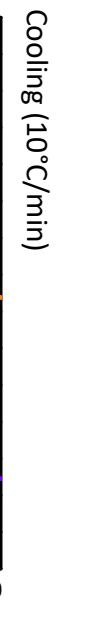

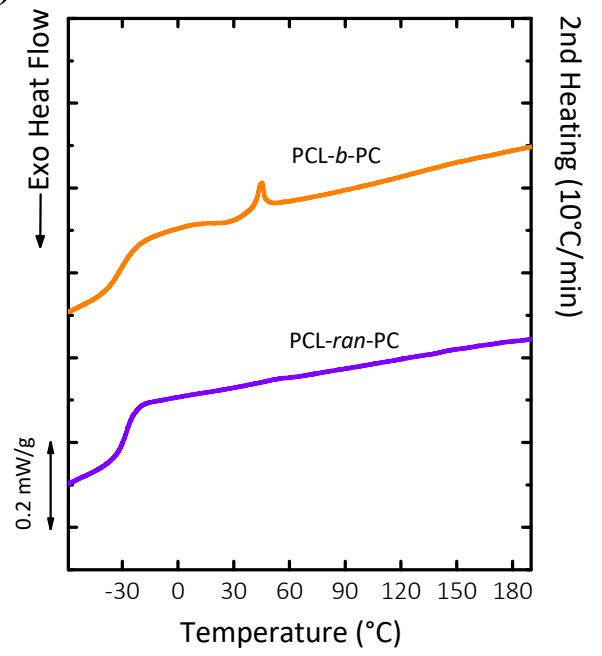

Figure 1. Non-isothermal DSC experiments on block and random copolymers. a) cooling curves at $10^{\circ} \mathrm{C} / \mathrm{min}$ from the melt state; $\boldsymbol{b})$ subsequent heating curves at $10^{\circ} \mathrm{C} / \mathrm{min}$. The curves have been normalized by the weight of the samples.

This item was downloaded from IRIS Università di Bologna (https://cris.unibo.it/)

When citing, please refer to the published version. 
As Table 2 shows, the block copolymer is in the weak segregation limit as its segregation strength is lower than 10 . This block copolymer is either forming a single phase melt or a weakly segregated melt. However, considering that only a single glass transition temperature has been detected by DSC, this block copolymer is most probably miscible both in the melt and in the glassy state. Even though the crystallization of the PCL component in the PCL- $b$-PC diblock copolymer does not occur upon cooling from the melt (see Figure 1a), it can undergo cold crystallization during the subsequent heating from the glassy state (see the small cold crystallization exotherm in Figure 1b). At a higher temperature of $44{ }^{\circ} \mathrm{C}$, the PCL block crystals melt (Figure $1 \mathrm{~b}$ ).

On the other hand, PCL-ran-PC does not show any evidence of crystallization of the PCL phase, as PCL sequences are too short to crystallize, as expected for random copolymers with compositions 60/40 (Table 2) [26].

Figure 2 shows thermogravimetric curves of PCL- $b$-PC and PCL-ran-PC copolymers and the respective derivative curves $\mathrm{dw} / \mathrm{dT}$ as a function of temperature, while Table 3 reports the respective values obtained from the curves.

Table 2. Molecular characteristic of the copolymers. The Flory-Huggins enthalpic segmental interaction parameter $(\chi)$; the overall degree of polymerization ( $N)$ of the copolymer calculated by $M_{n} / M_{0}$ where $M_{n}$ is the number average molecular weight of the entire copolymer, and $M_{0}$ is the molecular weight of the repeating unit (taking into account the molar composition of the copolymer); glass transition temperature ( $T_{g}$ ), temperature of crystallization $\left(T_{c}\right)$ and melting $\left(T_{m}\right)$ and relative enthalpy values.

\begin{tabular}{ccccccccc}
\hline Sample & $\chi$ & $N$ & $\chi N$ & $\begin{array}{c}T_{g} \\
\left({ }^{\circ} \mathrm{C}\right)\end{array}$ & $\begin{array}{c}T_{c} \\
\left({ }^{\circ} \mathrm{C}\right)\end{array}$ & $\begin{array}{c}\Delta H_{c} \\
(\mathrm{~J} / \mathrm{g})\end{array}$ & $\begin{array}{c}T_{m} \\
\left({ }^{\circ} \mathrm{C}\right)\end{array}$ & $\begin{array}{c}\Delta H_{m} \\
(\mathrm{~J} / \mathrm{g})\end{array}$ \\
\hline PCL-b-PC & 0.075 & 99.7 & 7.5 & -36 & 22 & 0.8 & 44 & 1 \\
PCL-ran-PC & 0.075 & 124.4 & 8.8 & -32 & - & - & - & - \\
\hline
\end{tabular}

This item was downloaded from IRIS Università di Bologna (https://cris.unibo.it/)

When citing, please refer to the published version. 
Both copolymers present a single degradation step, as a result of the formation of a single phase system in the melt state. However, the temperature at which PCL-ran-PC loses $10 \%$ of the total mass is $291{ }^{\circ} \mathrm{C}$, whereas for PCL- $b$-PC, it is $315^{\circ} \mathrm{C}$ (Table 3).

Considering that the two copolymers have a similar composition, the different degradation behavior is related to two factors. First of all, PCL-ran-PC has a lower molecular weight than PCL$b$-PC, and in the latter case, the longer polymer chains need a higher temperature to start degradation. At the same time, in PCL-ran-PC, the number of linkages between different sequences (i.e., PC and PCL blocks) is higher than in PCL- $b$-PC. Being PCL-PC linkage more susceptible to degradation than PC-PC or PCL-PCL linkages, PCL-ran-PC starts its degradation before PCL- $b$-PC.

a)

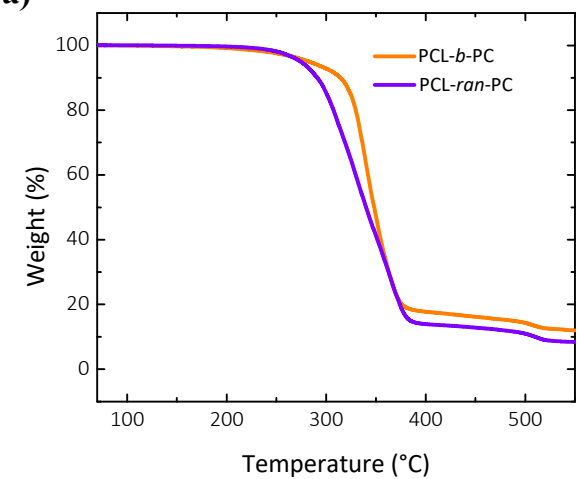

b)

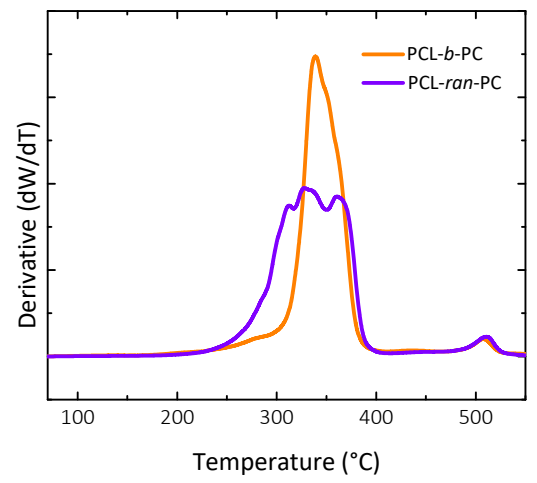

Figure 2. TGA curves for PCL-b-PC and PCL-ran-PC copolymers. a) Weight as a function of temperature. b) Derivative curves $(d w / d T)$ versus temperature.

Table 3. Data obtained from TGA analysis for PCL-b-PC and PCL-ran-PC copolymers.

\begin{tabular}{lcc}
\hline Sample & T $10 \%$ loss $\left({ }^{\circ} \mathrm{C}\right)$ & T derivative peak $\left({ }^{\circ} \mathrm{C}\right)$ \\
\hline PCL-b-PC & 315 & 339 \\
PCL-ran-PC & 291 & 329 \\
\hline
\end{tabular}

This item was downloaded from IRIS Università di Bologna (https://cris.unibo.it/) 


\subsection{Characterization of PLA/PCL blends}

\subsubsection{Preparation of the blends}

A constant PLA/PCL weight ratio of $80 / 20$ is used to obtain a balanced combination of stiffness and toughness. PCL-co-PC based copolymers were tested as compatibilizers by adding them at $10 \%$ by weight with respect to the minor phase. Thus, the final blends have an approximate composition of 80/20/2, weight ratio, PLA/PCL/PCL-co-PC. The blends were prepared by both solution and melt mixing.

It is worth noting that the two different blending techniques yield different morphologies and thermal behaviors of the resulting blends. In melt mixing, samples are heated at a temperature higher than $T_{m}$ and subjected to mechanical shear within the extruder. This process can cause a direct degradation of the polymer, which results in a shortening of the chains. On the other hand, in solution mixed samples, the blend components remain at room temperature in a hydrophobic solvent, which should prevent chain degradation. Because molecular weight has a key role in determining most of the properties of the blend, each of the following results must be correlated to a possible change in the molecular weight.

At the same time, upon solution or melt blending a different morphology of the blend can be obtained. In solution mixed blends, the size of the minor phase domains depends on the interfacial tension between the phases during segregation, upon solvent evaporation. On the other hand, in melt mixed samples, the size of the minor phase domains is also correlated with the balance between coalescence and mechanical breakup of the droplets and therefore to the processing parameters. As a general result, in solution mixed samples, the size of the minor phase domains is typically larger than in melt mixed blends.

This item was downloaded from IRIS Università di Bologna (https://cris.unibo.it/)

When citing, please refer to the published version. 


\subsubsection{Molecular weight analysis}

Table 4 reports number and weight average molecular weights for neat PLA and for all the blends prepared in this work.

Table 4. Number and weight average molecular weights of melt mixed and solvent mixed samples.

\begin{tabular}{cccc}
\hline Sample & $M_{n}(\mathrm{KDa})$ & $M_{w}(\mathrm{KDa})$ & $\mathrm{D}$ \\
\hline PLA(m) & 123 & 153 & 1.2 \\
PLA/PCL(m) & 111 & 160 & 1.4 \\
PLA/PCL/PCL- $b$-PC(m) & 81 & 113 & 1.4 \\
PLA/PCL/PCL-ran-PC(m) & 38 & 64 & 1.7 \\
PLA(s) & 117 & 179 & 1.5 \\
PLA/PCL(s) & 116 & 178 & 1.4 \\
PLA/PCL/PCL- $b$-PC(s) & 132 & 179 & 1.4 \\
PLA/PCL/PCL-ran-PC(s) & 127 & 184 & \\
\hline
\end{tabular}

In all solution-blended samples, the overall weight average molecular weight does not change upon blending and remains unchanged and similar to the value reported for neat PLA. As there is four times more quantity of PLA in the blends as PCL, changes in average molecular weights are mostly due to changes in PLA molecular weight. For detailed considerations on how to interpret the GPC measurements performed to the blends, please see the Supplementary Information.

On the contrary, in melt blended samples that contain copolymers, the molecular weight is always much lower than expected. The molecular weight of neat PLA and PLA/PCL decrease slightly when they are melt processed. However, copolymers addition causes a dramatic degradation of the polymers chains. In particular, in PLA/PCL/PCL- $b$-PC, the overall $M_{w}$ value decreased to $113 \mathrm{KDa}$ after melt processing while in the PLA/PCL/PCL-ran-PC case, the $M_{w}$ drop even further to $64 \mathrm{KDa}$. Considering that all melt blended samples have been processed in the same way, such reduction of the molecular weight must be induced by copolymer addition.

PCL degrades much less and more slowly than PLA [27]. Therefore, it is possible that PCLco-PC based copolymers, characterized by low molecular weights $(18.5$ and $14.6 \mathrm{~kg} / \mathrm{mol}$, see above and Table S1), are more susceptible to degradation than the PLA phase at the melt blending conditions This item was downloaded from IRIS Università di Bologna (https://cris.unibo.it/) 
employed. Once degraded to oligomers, they can undergo transesterification with PLA chains causing important molecular weight reductions.

As confirmation, it is worth noting that the copolymer characterized by being random and by having the lowest molecular weight should be the most susceptible to degradation (i.e., PCL-ran-PC, see molecular weight in Table S1 and thermograms in Figure 2). The addition of this random copolymer causes the highest molecular weight reduction of PLA chains in the melt-mixed blends. To confirm such hypothesis, thermogravimetric analysis was performed.

\subsubsection{Thermogravimetric analysis}

Figure 3 shows TGA thermograms and respective derivatives $(d w / d T)$ for neat PLA, PLA/PCL, and PLA/PCL/PCL-co-PC, for both blends obtained by melt and solution mixing, while Table 5 reports the corresponding temperatures of $10 \%$ loss and derivative peak maximum.

Table 5. Data obtained for TGA analyses for neat PLA, PLA/PCL, and PLA/PCL/PCL-co-PC blends obtained by both melt and solution mixing.

\begin{tabular}{ccc}
\hline Sample & T $10 \%$ loss $\left({ }^{\circ} \mathrm{C}\right)$ & T derivate peak $\left({ }^{\circ} \mathrm{C}\right)$ \\
\hline PLA(m) & 340 & 370 \\
PLA/PCL $(\mathrm{m})$ & 345 & 368 \\
PLA/PCL/PCL- $b$-PC(m) & 280 & 306 \\
PLA/PCL/PCL-ran-PC(m) & 272 & 290 \\
PLA(s) & 334 & 370 \\
PLA/PCL(s) & 339 & 369 \\
PLA/PCL/PCL-b-PC(s) & 317 & 364 \\
PLA/PCL/PCL-ran-PC(s) & 310 & 365 \\
\hline
\end{tabular}

Neat PLA starts its degradation at temperatures above $305^{\circ} \mathrm{C}$, in agreement with the study of Carrasco et al. [28] and without important differences between solution and melt mixed samples. Likewise, the PLA phase within PLA/PCL blends is not affected by the processing condition (i.e., 
solution or melt blending) since in both blends, the PLA phase has a similar molecular weight (see Table 4), and the characteristic degradation temperatures are in the same temperature range (see Table $5)$.

a)

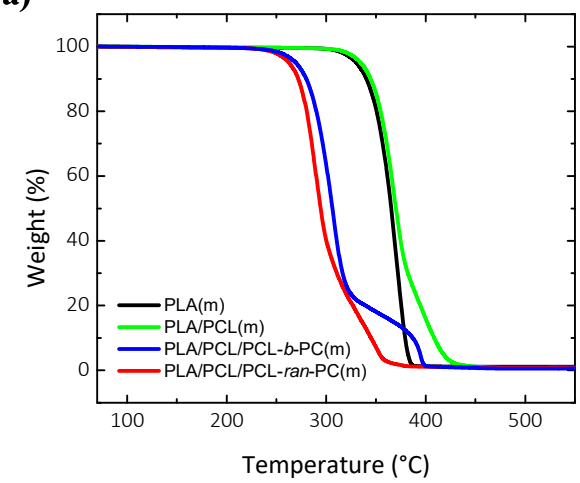

c)

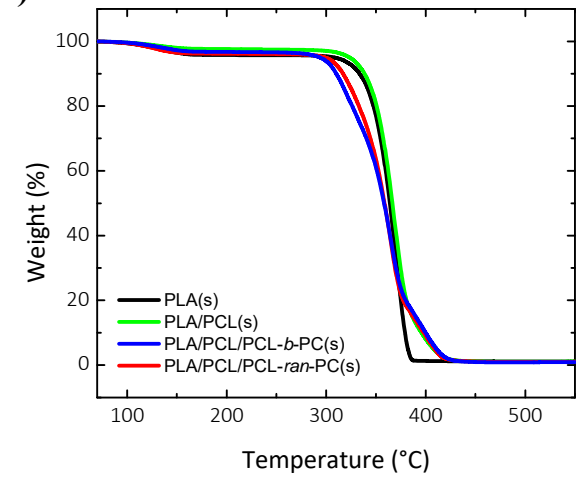

b)

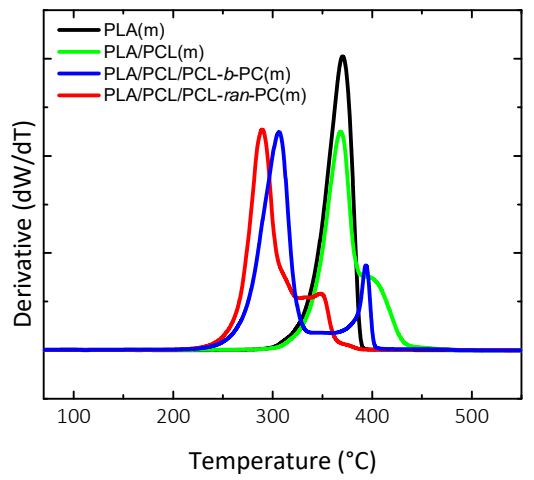

d)

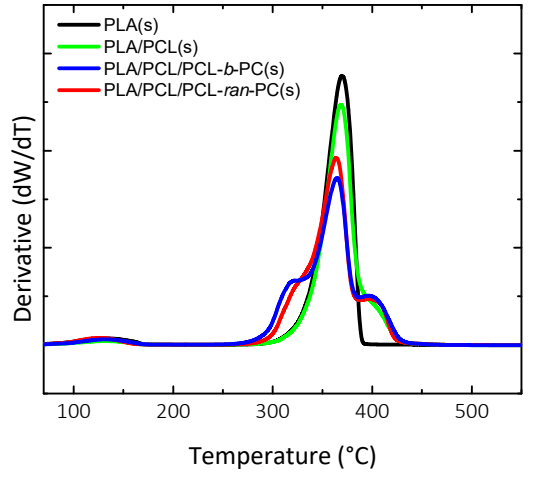

Figure 3. TGA thermograms of PLA and the indicated blends. a) Weight reduction of neat PLA and PLA/PCL, $P L A / P C L / P C L-c o-P C$ blends, obtained by melt blending. b) Derivative curves ( $d w / d T)$ of neat PLA and PLA/PCL, PLA/PCL/ PCL-co-PC blends, obtained by melt blending. c) Weight reduction of neat PLA and PLA/PCL, PLA/PCL/PCL-co-PC blends, obtained by solution blending. d) Derivative curves (dw/dT) of neat PLA and PLA/PCL, PLA/PCL/PCL-co-PC blends, obtained by solution blending.

On the other hand, the degradation temperature of PLA/PCL/PCL-co-PC strongly depends on the blend preparation method (as reflected by the differences in molecular weight, see Table 4). According to Table 5, PLA/PCL/PCL- $b$-PC(s) looses the $10 \%$ of the total mass at $\mathrm{T}=317^{\circ} \mathrm{C}$, whereas PLA/PCL/PCL- $b-\mathrm{PC}(\mathrm{m})$ at $\mathrm{T}=280{ }^{\circ} \mathrm{C}$. At the same time, PLA/PCL/PCL-ran-PC(s) looses the $10 \%$ 
of the total mass at $\mathrm{T}=310^{\circ} \mathrm{C}$, whereas PLA/PCL/PCL-ran-PC(m) looses the $10 \%$ of the total mass at $\mathrm{T}=272{ }^{\circ} \mathrm{C}$.

The TGA results indicate that the blends containing the copolymers degrade at much lower temperatures than those without copolymers. This confirms that the presence of PCL-co-PC decreases the stability of the PLA blend component.

\subsubsection{Morphological analysis}

Figure 4 shows SEM micrographs of the cryogenically fractured surfaces of PLA/PCL and PLA/PCL/PCL-co-PC samples obtained both by melt and solution blending. Table 6 reports average PCL particles size within the blend, measured by counting at least 100 particles for both types of blends.

A sea-island morphology, typical of immiscible blends, is observable in all cases. PLA conforms the matrix, while PCL is dispersed in droplets. The cavities observed in all the micrographs are due to the interfacial debonding between PLA and PCL during the fracture, confirming the immiscibility between phases.

The large differences in PCL particle size (see Table 6) are related to the blending technique. When two immiscible polymers are blended, during melt mixing, one phase is mechanically dispersed inside the other. The size and shape of the minor phase particles depend on the competition between droplet breakup and coalescence. On the other hand, in solution mixing the two polymer phases are dissolved in a common solvent, and after some time needed to obtain a homogeneous solution, the solvent is evaporated. The absence of mechanical shear is reflected in a general increase of the minor phase particles size and dispersion $\left(D_{p}\right)$.

According to Table 6, in all cases (both melt and solution mixed blends) the PCL particles size does not significantly change upon copolymers addition. This indicates that the copolymers do not

This item was downloaded from IRIS Università di Bologna (https://cris.unibo.it/)

When citing, please refer to the published version. 
migrate to the PLA-PCL interface, but, rather, are probably dispersed or dissolved in the PCL phase. The PCL-co-PC copolymers are chemically more compatible with the PCL phase rather than the PLA phase. PC is known to be miscible with PCL depending on the molecular weight [29]. As both copolymers obtained have a rather low molecular weight $(15-18 \mathrm{~kg} / \mathrm{mol})$, their solubility in PCL is very likely.

Table 6. Number average $\left(d_{n}\right)$ and volume average $\left(d_{v}\right)$ particle diameters, particle size distributions $\left(D_{p}\right)$ and standard deviation (SD) of the PCL phase in PLA/PCL and PLA/PCL/PCL-co-PC blends obtained by both melt and solution mixing.

\begin{tabular}{ccccc}
\hline Sample & $d_{n}(\mu \mathrm{m})$ & $d_{v}(\mu \mathrm{m})$ & $D_{p}$ & $\mathrm{SD}$ \\
\hline PLA/PCL(m) & 1.4 & 1.7 & 1.3 & 0.45 \\
PLA/PCL/PCL-b-PC(m) & 1.5 & 2.0 & 1.3 & 0.49 \\
PLA/PCL/PCL-ran-PC(m) & 1.7 & 2.3 & 1.4 & 0.52 \\
PLA/PCL(s) & 5.6 & 11.0 & 2.0 & 1.36 \\
PLA/PCL/PCL- $b$-PC(s) & 3.2 & 9.8 & 3.1 & 0.96 \\
PLA/PCL/PCL-ran-PC(s) & 6.2 & 13.2 & 2.1 & 2.48 \\
\hline
\end{tabular}
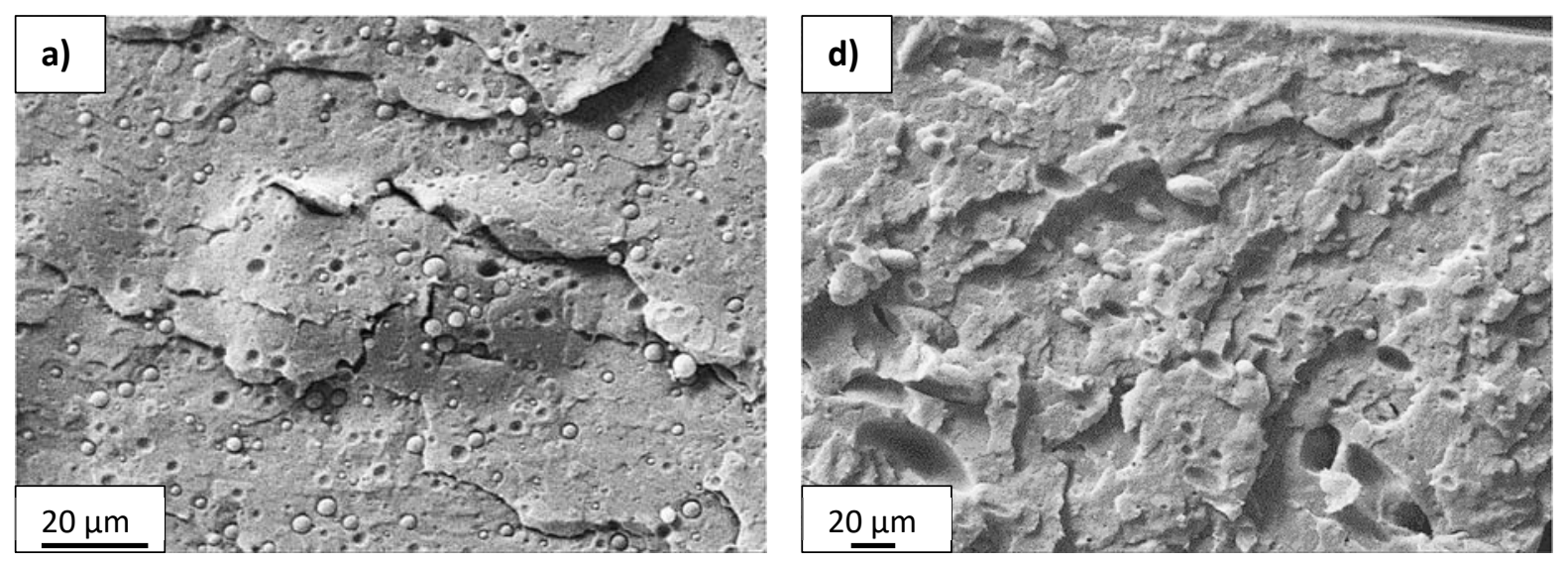

This item was downloaded from IRIS Università di Bologna (https://cris.unibo.it/) 

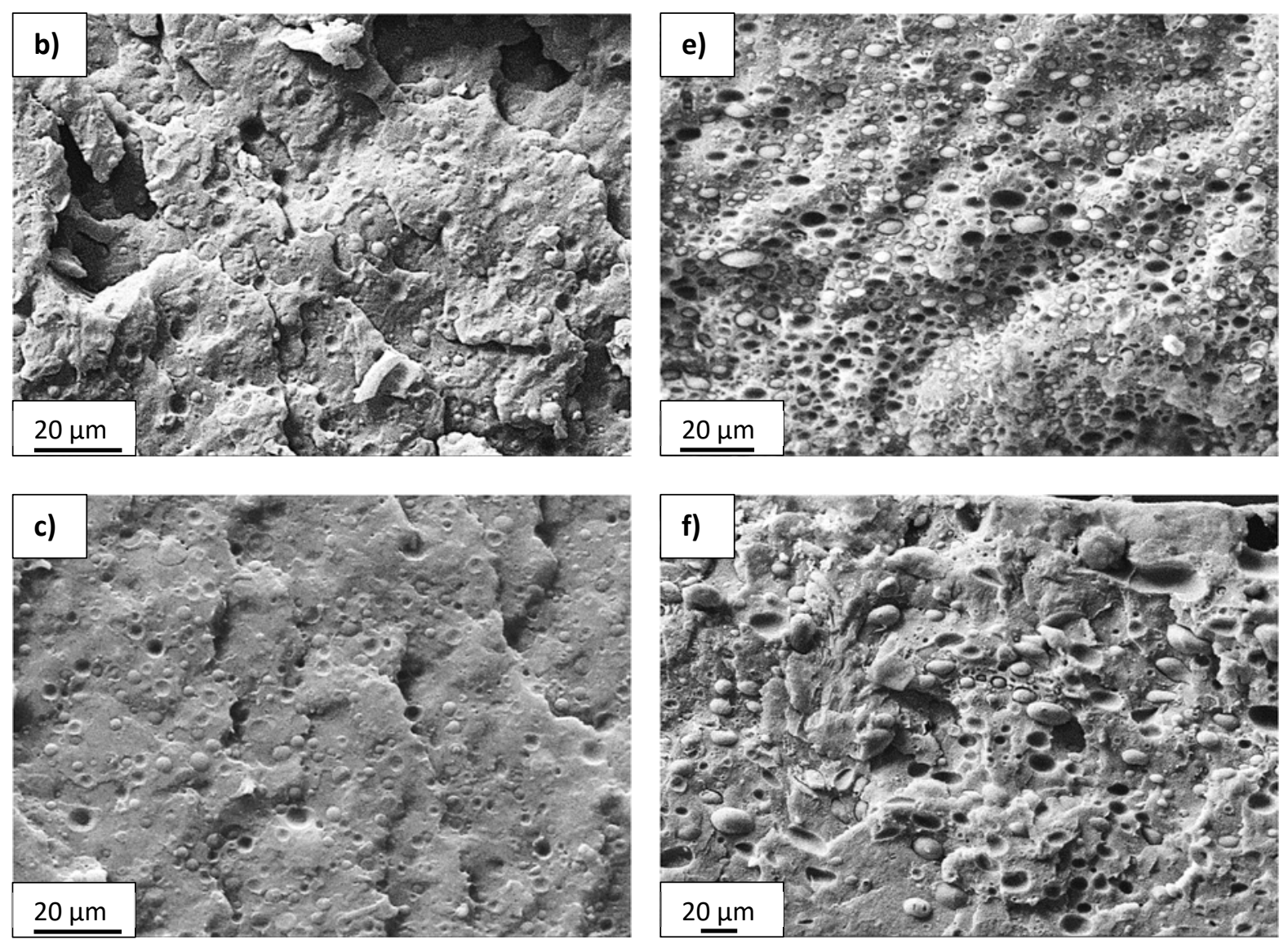

Figure 4. SEM micrographs of the cryogenically fractured surfaces of a) $P L A / P C L(m)$, b) $P L A / P C L / P C L-b$ $P C(m)$, c) $P L A / P C L / P C L-r a n-P C(m)$ blends obtained by melt mixing and d) $P L A / P C L(s)$, e) $P L A / P C L / P C L-$ $b-P C(s)$, f) PLA/PCL/PCL-ran-PC(s) blends obtained by solution mixing.

\subsubsection{Non-isothermal DSC analysis-Cooling from the melt state}

Figure 5 shows DSC cooling scans from the melt at $10^{\circ} \mathrm{C} / \mathrm{min}$ for melt mixed and solution mixed samples, while Table 7 reports the corresponding values of thermal transitions recorded during the scans.

The glass transition temperature $\left(T_{g}\right)$ of PLA or the PLA component in the blends can be seen in Figure 5, as a characteristic jump in heat capacity in the range $59-61^{\circ} \mathrm{C}$. Upon blending with PCL, both in solution and melt mixing, the $T_{g}$ of the PLA phase remains constant. A constant $T_{g}$ value evidences blend immiscibility. Otherwise, a $T_{g}$ depression would be detected, as a result of the interaction of PLA with the more flexible PCL chains (PCL $T_{g}=-60{ }^{\circ} \mathrm{C}$ ).

This item was downloaded from IRIS Università di Bologna (https://cris.unibo.it/)

When citing, please refer to the published version. 
Neat PCL crystallizes during cooling with a sharp exothermic peak, at $26{ }^{\circ} \mathrm{C}$ in the case of PCL(m) and at $29{ }^{\circ} \mathrm{C}$ in the case of PCL(s). The differences could be attributed to impurities transfer from the solvent to PCL. It must be remembered that the peak crystallization temperature upon cooling from the melt is proportional to the nucleation density. For bulk PCL samples, the nucleation occurs on existing heterogeneities in the material.

In the case of melt mixed PLA/PCL(m) blend, PCL crystallization is fractionated into two peaks at $24{ }^{\circ} \mathrm{C}$ and $35{ }^{\circ} \mathrm{C}$, whereas in solution mixed PLA/PCL(s) the same phenomenon does not happen. The fractionation of the crystallization is a common occurrence in immiscible blends. It happens when the number of droplets of a crystallizable phase is larger or of the same order of magnitude as the number of active heterogeneities in the bulk polymer before being dispersed. The smaller the droplets, the more difficult would be to find active heterogeneities in each droplet. For more information on fractionated crystallization, see refs. [23,30-32]. In melt mixed PLA/PCL(m) blend, the first crystallization peak at $35{ }^{\circ} \mathrm{C}$ corresponds to the crystallization of PCL droplets that have been nucleated by similarly active heterogeneities as those present in the bulk polymer. In fact, during melt blending, impurities transfer to the PCL phase can also occur, and this may explain the higher $T_{c}$ value. The second crystallization peak at $24{ }^{\circ} \mathrm{C}$ is due to the crystallization of PCL droplets nucleated by less active heterogeneities [23,30-32].

On the other hand, in solution mixed PLA/PCL(s) blend, the same phenomenon does not happen as PCL droplet sizes are much larger. Therefore the number of droplets per unit volume is smaller than the number of heterogeneities in bulk PCL [23,30-32].

In the case of the mixed blends containing PCL-co-PC based copolymers (i.e., PLA/PCL/PCL$b$-PC(m) and PLA/PCL/PCL-ran-PC(m)), a single PCL crystallization peak at $36{ }^{\circ} \mathrm{C}$ is detected, even though the particle size is the same, as that of the corresponding melt mixed PLA/PCL(m) blend (see

This item was downloaded from IRIS Università di Bologna (https://cris.unibo.it/)

When citing, please refer to the published version. 
Table 6). In this case, all PCL droplets crystallize at higher temperatures, since the addition of the copolymers in the melt state probably causes a transfer of heterogeneities to the PCL phase [33].

a)

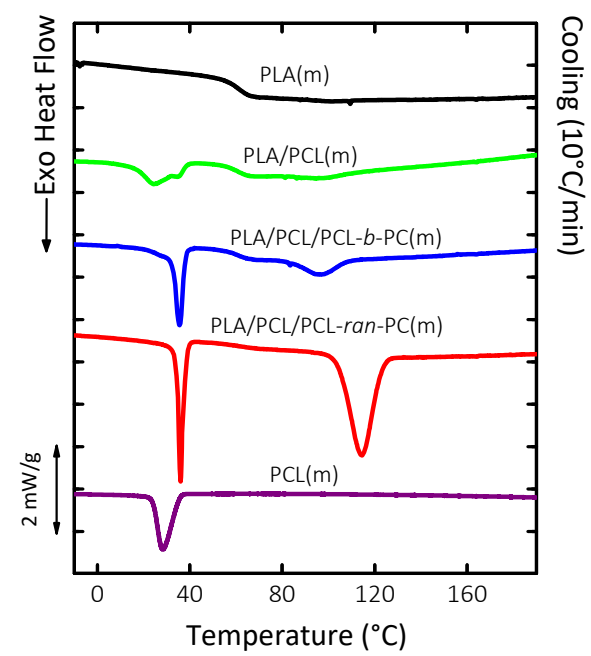

b)

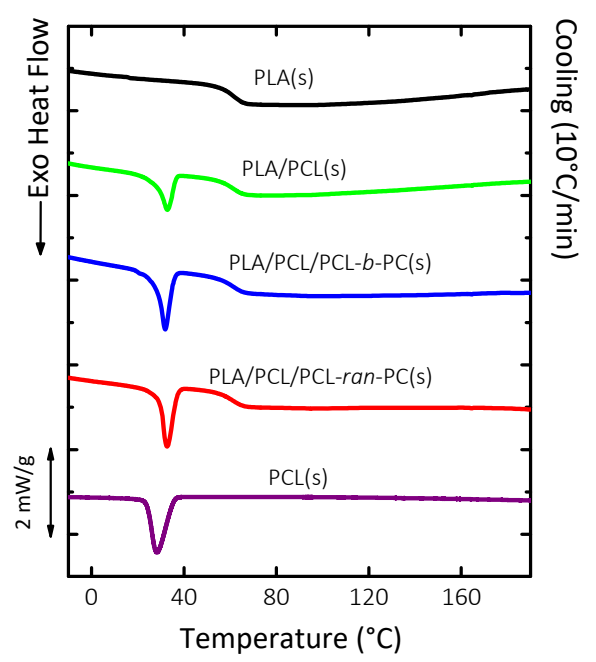

Figure 5. Non-isothermal DSC experiments curves. Cooling curves at $10^{\circ} \mathrm{C} / \mathrm{min}$ from the melt state of neat PLA, neat PCL, PLA/PCL and PLA/PCL/PCL-co-PC blends obtained by melt mixing a) and by solution mixing b). The curves are normalized by the weight of the samples.

In the case of solution mixed blends containing PCL-co-PC based copolymers (i.e., PLA/PCL/PCL- $b$-PC(s) and PLA/PCL/PCL-ran-PC(s) blends) a single PCL crystallization peak is detected.

According to Figure 5, neat PLA does not crystallize during cooling at the scanning rate employed, both in the samples obtained by solution and melt blending. This is because the amount of D-units in PLA (i.e., PLA 4032D 1.2-1.6\% of D-unit) is too high to allow crystallization at the employed scanning rates [34].

Table 7. Thermal properties obtained from non-isothermal DSC cooling at $10{ }^{\circ} \mathrm{C} / \mathrm{min}$. The enthalpies of crystallization and melting have been normalized by the weight fraction of the samples.

PCL PLA

This item was downloaded from IRIS Università di Bologna (https://cris.unibo.it/)

When citing, please refer to the published version. 


\begin{tabular}{|c|c|c|c|c|c|c|}
\hline Sample & Comp & $\begin{array}{c}T_{c} \\
\left({ }^{\circ} \mathrm{C}\right)\end{array}$ & $\begin{array}{l}\Delta H_{c} \\
(\mathrm{~J} / \mathrm{g})\end{array}$ & $\begin{array}{c}T_{g} \\
\left({ }^{\circ} \mathrm{C}\right)\end{array}$ & $\begin{array}{c}T_{c} \\
\left({ }^{\circ} \mathrm{C}\right)\end{array}$ & $\begin{array}{l}\Delta H_{c} \\
(\mathrm{~J} / \mathrm{g})\end{array}$ \\
\hline $\operatorname{PLA}(\mathrm{m})$ & 100 & - & - & 59.6 & - & - \\
\hline PLA/PCL(m) & $80 / 20$ & $24.3 / 34.5$ & $8.7 / 36.1$ & 59.3 & 94.3 & 4.1 \\
\hline PLA/PCL/PCL- $b$-PC(m) & $80 / 20 / 2$ & 35.5 & 49.9 & 59.6 & 96.5 & 9.1 \\
\hline PLA/PCL/PCL-ran-PC(m) & $80 / 20 / 2$ & 36.0 & 56.8 & 61.9 & 114.5 & 42.0 \\
\hline $\operatorname{PCL}(\mathrm{m})$ & 100 & 25.9 & 45.7 & - & - & - \\
\hline $\operatorname{PLA}(\mathrm{s})$ & 100 & - & - & 59.6 & - & - \\
\hline PLA/PCL(s) & $80 / 20$ & 32.9 & 26 & 59.5 & - & - \\
\hline PLA/PCL/PCL- $b$-PC(s) & $80 / 20 / 2$ & 31.9 & 41.5 & 59.4 & - & - \\
\hline PLA/PCL/PCL-ran-PC(s) & $80 / 20 / 2$ & 32.7 & 43.2 & 59.7 & - & - \\
\hline $\operatorname{PCL}(\mathrm{s})$ & 100 & 28.8 & 57.2 & - & - & - \\
\hline
\end{tabular}

The PLA component crystallizes only in the melt mixed blends (Figure 5a), while no crystallization exotherms are detected in solution mixed samples (Figure 5b). Considering that no effect of increased miscibility between PLA and PCL phases is detected upon copolymers addition, the reason for this behavior derives from the differences of processing condition between solution and melt mixing. As previously explained, PLA thermo-mechanical degradation can occur during melt blending with PCL. As a result, the increases in chain mobility upon molecular weight reduction facilitates crystallization during cooling from the melt. As confirmation, it is worth noting that the blend characterized by lowest PLA phase molecular weight (i.e., PLA/PCL/PCL-ran-PC(m)) is the one that presents the largest crystallization enthalpy. This is the blend where the PLA phase degrades the most as demonstrated above by GPC and TGA results.

\subsubsection{Non-isothermal DSC analysis-Second Heating}

Figure 6 shows second heating DSC curves at $10{ }^{\circ} \mathrm{C} / \mathrm{min}$ for neat components and all the blends. Table 8 shows the corresponding calorimetric data. 
a)

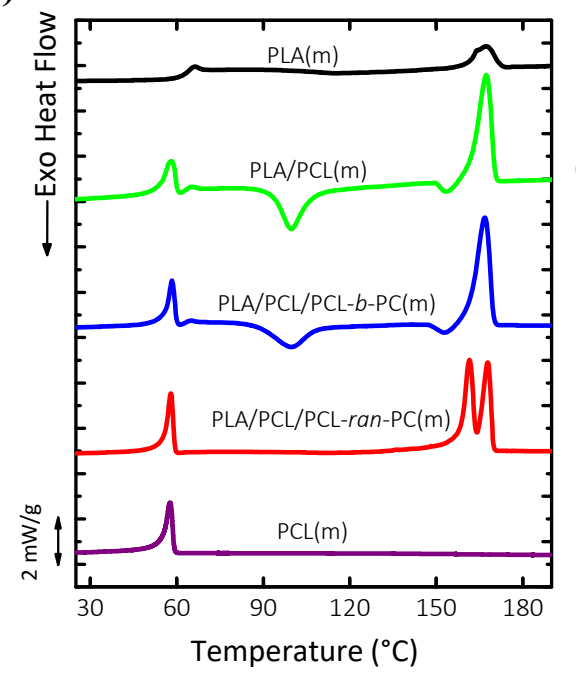

b)

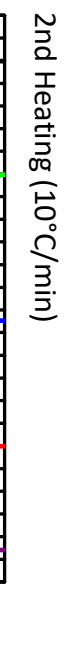

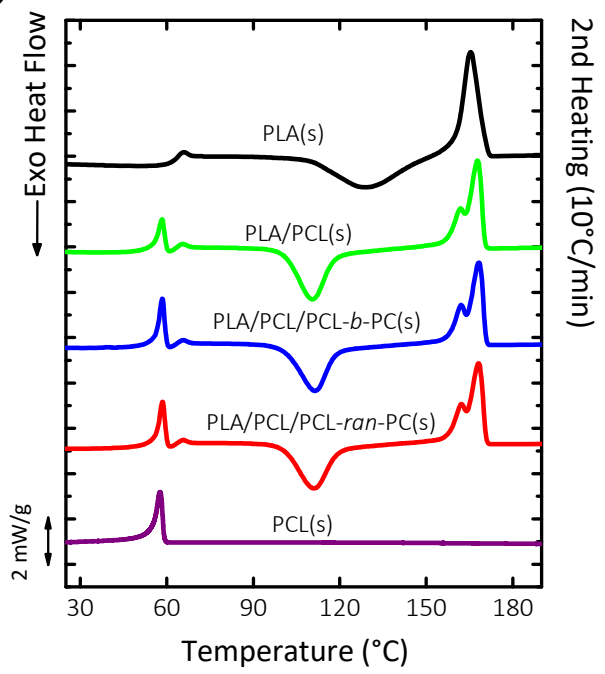

Figure 6. Non-isothermal DSC experiments. Second heating curves at $10^{\circ} \mathrm{C} / \mathrm{min}$ of neat PLA, neat PCL, PLA/PCL, and PLA/PCL/PCL-Co-PC blends obtained by melt mixing a) and by solution mixing $\boldsymbol{b}$ ). The curves have been normalized by the weight of the samples.

Neat PLA undergoes cold crystallization and subsequent fusion of the produced crystals at $115^{\circ} \mathrm{C}$ and $167{ }^{\circ} \mathrm{C}$ respectively for PLA(m), and $129{ }^{\circ} \mathrm{C}$ and $166^{\circ} \mathrm{C}$ for PLA(s). In any case, the direct correspondence of enthalpy of crystallization and melting indicate that PLA remains completely amorphous during the previous cooling in both blends (see Table 8).

Upon blending with PCL, the cold crystallization exothermic peak is sharper and shifted to lower temperatures for both solution and melt mixed samples. This occurs because PCL can nucleate PLA during aging below $T_{g}$. This fact was already demonstrated in our previous work [18] where the decrease in $T_{c c}$ for PLA upon blending with PCL in solution mixed samples was due to a nucleation effect of PCL on the glassy PLA matrix.

The melting temperature of the PLA phase is maintained almost identical in all samples, except in PLA/PCL/PCL-ran-PC(m), where a double melting peak is detected. This could be a consequence of reorganization during the heating scan or to the presence of two crystalline forms (i.e., $\alpha$ and $\alpha$ prime forms) [35-37]. PLA double melting observed is commonly ascribed to melting 
and recrystallization processes that occur during the heating scan [36,37]. If polymorphism is present (alpha and alpha prime crystalline forms) it would have to be determined by Wide Angle X-ray Diffraction.

As Table 4 shows, the molecular weight of the samples is not the same. In melt mixed blends, and especially in PLA/PCL/PCL-ran-PC(m), a lower molecular weight was found, and thus a lower melting temperature could have been anticipated. However, no significant change in melting temperature has been detected.

Table 8. Thermal properties obtained from non-isothermal DSC heating at $10^{\circ} \mathrm{C} / \mathrm{min}$. The enthalpies of crystallization and melting have been normalized by the weight fraction of the samples.

\begin{tabular}{|c|c|c|c|c|c|c|c|c|c|}
\hline \multicolumn{10}{|c|}{ Second Heating } \\
\hline \multirow[b]{2}{*}{ Sample } & \multirow[b]{2}{*}{$\begin{array}{l}\text { Comp } \\
\text { w/w }\end{array}$} & \multicolumn{2}{|c|}{ PCL } & \multicolumn{6}{|c|}{ PLA } \\
\hline & & $\begin{array}{c}T_{m} \\
\left({ }^{\circ} \mathrm{C}\right)\end{array}$ & $\begin{array}{l}\Delta H_{m} \\
(\mathrm{~J} / \mathrm{g})\end{array}$ & $\begin{array}{c}T_{c c} \\
\left({ }^{\circ} \mathrm{C}\right)\end{array}$ & $\begin{array}{l}\Delta H_{c c} \\
(\mathrm{~J} / \mathrm{g})\end{array}$ & $\begin{array}{c}T_{c c} \\
\left({ }^{\circ} \mathrm{C}\right)\end{array}$ & $\begin{array}{l}\Delta H_{c c} \\
(\mathrm{~J} / \mathrm{g})\end{array}$ & $\begin{array}{c}T_{m} \\
\left({ }^{\circ} \mathrm{C}\right)\end{array}$ & $\begin{array}{l}\Delta H_{m} \\
(\mathrm{~J} / \mathrm{g})\end{array}$ \\
\hline $\operatorname{PLA}(\mathrm{m})$ & 100 & - & - & 115.2 & 8.5 & - & - & 167.3 & 9.0 \\
\hline PLA/PCL(m) & $80 / 20$ & 58.0 & 40.1 & 99.8 & 25.6 & 153.6 & 2.9 & 167.3 & 36.9 \\
\hline PLA/PCL/PCL- $b-P C(\mathrm{~m})$ & $80 / 20 / 2$ & 58.4 & 42.2 & 99.7 & 21.4 & 152.9 & 2.8 & 166.8 & 39.0 \\
\hline PLA/PCL/PCL-ran-PC(m) & $80 / 20 / 2$ & 57.9 & 54.4 & 117.4 & 3.3 & - & - & $161.6 / 167$ & $27.3 / 19.5$ \\
\hline $\operatorname{PCL}(\mathrm{m})$ & 100 & 55.3 & 46.6 & - & - & - & - & - & - \\
\hline PLA(s) & 100 & - & - & 128.7 & 34.0 & - & - & 165.5 & 34.0 \\
\hline PLA/PCL(s) & $80 / 20$ & 58.4 & 30.0 & 110.5 & 35.8 & - & - & $161.8 / 167$ & $14.3 / 23.5$ \\
\hline PLA/PCL/PCL- $b$-PC(s) & $80 / 20 / 2$ & 58.4 & 40.7 & 111.3 & 31.5 & - & - & $162.3 / 168$ & $12.1 / 21.7$ \\
\hline PLA/PCL/PCL-ran-PC(s) & $80 / 20 / 2$ & 58.6 & 42.9 & 111.0 & 32.3 & - & - & $162.1 / 168$ & $12.7 / 21.4$ \\
\hline PCL(s) & 100 & 57.8 & 63.2 & - & - & - & - & - & - \\
\hline
\end{tabular}

However, it must be considered that a change in the molecular weight does not necessarily provide a change in the melting temperature. In the case of PLA, $T_{m}$ increases until reaching an asymptotical dependence with $M_{n}$ at values higher than $50 \mathrm{kDa}$ [34]. Since in all the blends, the PLA component has a high enough molecular weight, $T_{m}$ is not sensible to $M_{n}$ variation, in the range of molecular weights explored.

This item was downloaded from IRIS Università di Bologna (https://cris.unibo.it/)

When citing, please refer to the published version. 


\subsubsection{Spherulitic growth kinetics of the PLA phase}

Figure 7 shows PLOM micrographs of neat PLA and PLA containing samples obtained by melt blending, while Figure 8 presents the micrographs of the corresponding samples obtained by solution mixing. In all cases, the PLA spherulites are negative and show the typical Maltese cross, as has been previously reported in the literature [38-39].
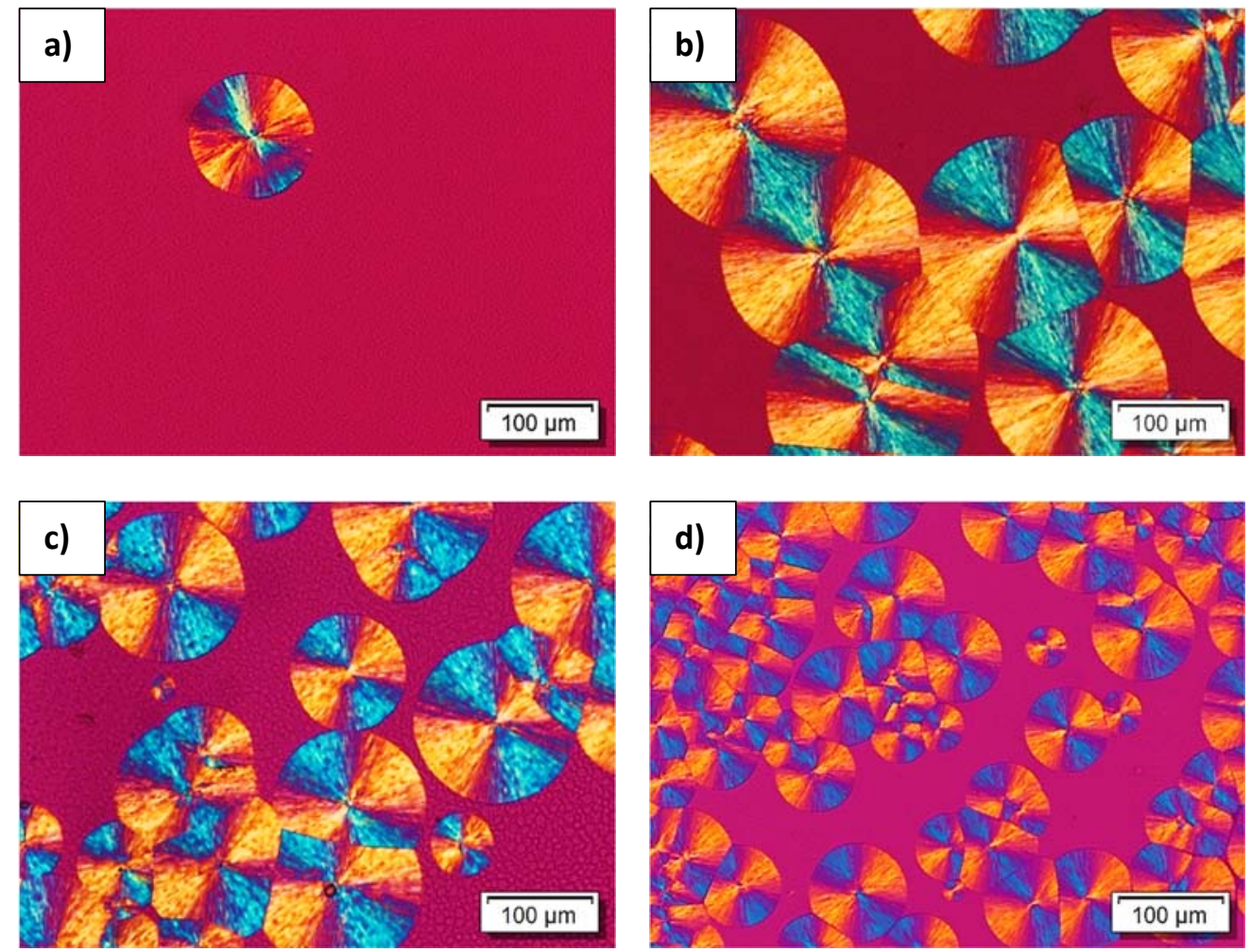

Figure 7. $P L O M$ micrographs of a) $P L A(m)$ b) $P L A / P C L(m)$ c) $P L A / P C L / P C L-b-P C(m)$ d) $P L A / P C L / P C L-$ ran- $P C(m)$ recorded at $130^{\circ} \mathrm{C}$ and after 25 minutes from the beginning of crystallization.

In all samples, PLA spherulites grow linearly with time, indicating that no diffusion problems at the growth front were induced by blending. The spherulitic growth rate $G\left(\mu \mathrm{m} \min ^{-1}\right)$ was thus calculated from the slope of the line obtained plotting the spherulitic radius $(\mu \mathrm{m})$ against time (min). 
Figure 9 shows $G$ as a function of crystallization temperature $T_{c}$ for neat PLA and samples obtained by melt blending, while in Figure 10, $G$ as a function of crystallization temperature $T_{c}$ is reported for the corresponding samples obtained by solution mixing. The values of $G$ at different crystallization temperatures were fitted by an arbitrary function to guide the eye.
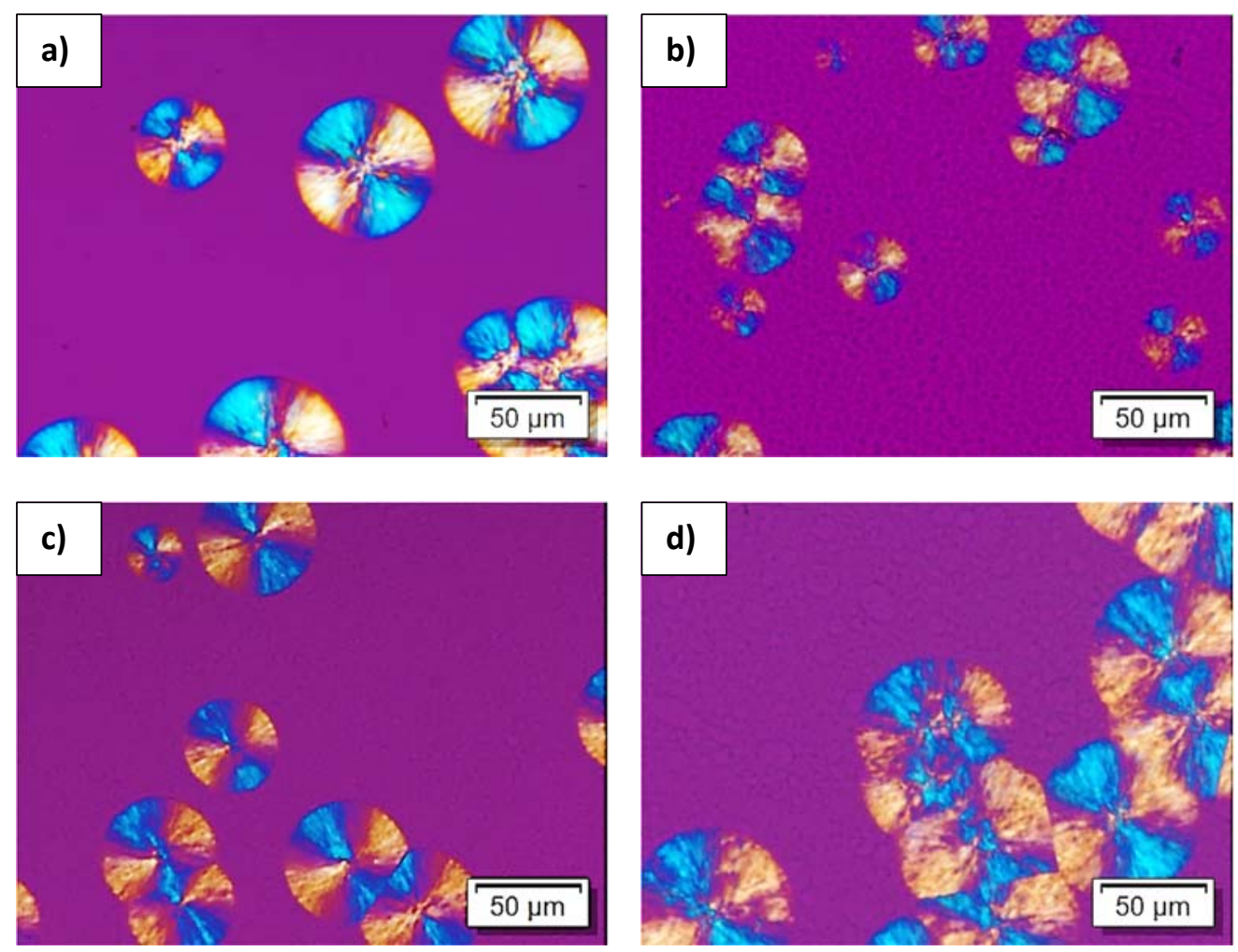

Figure 8. PLOM micrographs of a) $P L A(s)$, b) $P L A / P C L(s)$, c) $P L A / P C L / P C L-b-P C(s)$ d) $P L A / P C L / P C L-$ ran-PC(s) recorded at $130^{\circ} \mathrm{C}$ and after 25 minutes from the beginning of crystallization.

All the samples show the expected bell shape behavior of $G$ versus $T_{c}$, as a result of the competition between secondary nucleation and diffusion [39]. Comparing Figure 9 with Figure 10, it is possible to see that for PLA/PCL/PCL- $b$-PC(m) and PLA/PCL/PCL-ran-PC(m) blends, $G$ reaches values much larger than for neat PLA (in the case of PLA/PCL/PCL-ran-PC(m) a threefold increase of $G$ is even detected). On the other hand, in the corresponding solution mixed sample (i.e., 
PLA/PCL/PCL- $b$-PC(s) and PLA/PCL/PCL-ran-PC(s)) the values of $G$ are almost the same as for neat PLA.

We do not find any evidence of miscibility between PLA and PCL in our blends (both in melt and solution mixed samples). Hence, the differences in growth kinetics must be due to the different molecular weights of PLA chains within the samples.

In semicrystalline polymers, the isothermal spherulitic growth rate decreases when molecular weight increases (in the molecular weight range larger than the critical molecular weight for entanglement formation), as chain diffusion slows down. At molecular weights exceeding $100 \mathrm{kDa}$, the spherulitic growth rate of PLA tends to stabilize and becomes constant with further increases in molecular weight in the range between 100 and $300 \mathrm{kDa}[40]$.

As reported in Table 4, in PLA/PCL/PCL- $b$-PC(m) and PLA/PCL/PCL-ran-PC(m), the PLA phase has a lower molecular weight than in the other blends, because of the increased degradation of the PLA chains (i.e., $81 \mathrm{KDa}$ and $38 \mathrm{KDa}$ in comparison with the other blends where $M_{n}$ is always around $130 \mathrm{KDa})$. As a result, in PLA/PCL/PCL-b-PC(m) and PLA/PCL/PCL-ran-PC(m), the spherulitic growth rate is higher.

This item was downloaded from IRIS Università di Bologna (https://cris.unibo.it/) 


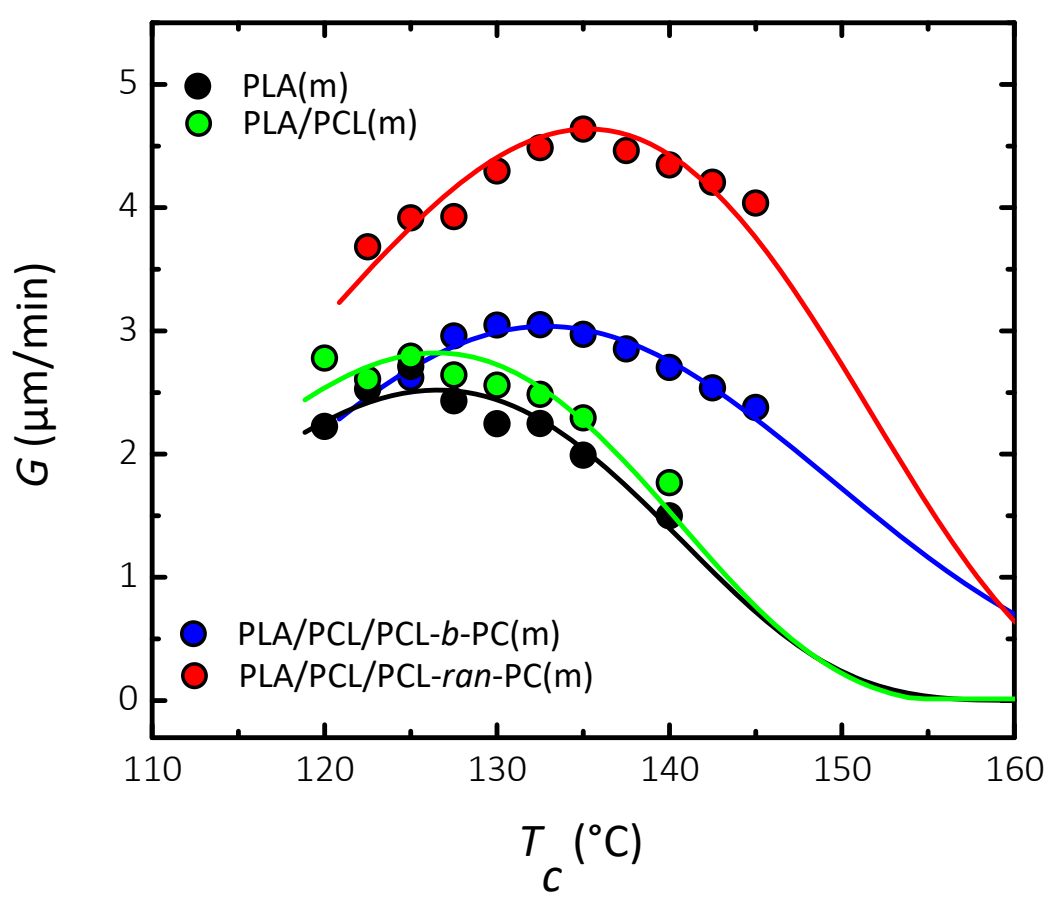

Figure 9. Spherulitic growth rate $G$ as a function of isothermal crystallization temperature $T_{c}$ for neat PLA and PLA phase within PLA/PCL and PLA/PCL/PCL-co-PC melt mixed blends. The solid lines represent an arbitrary fit to guide the eye.

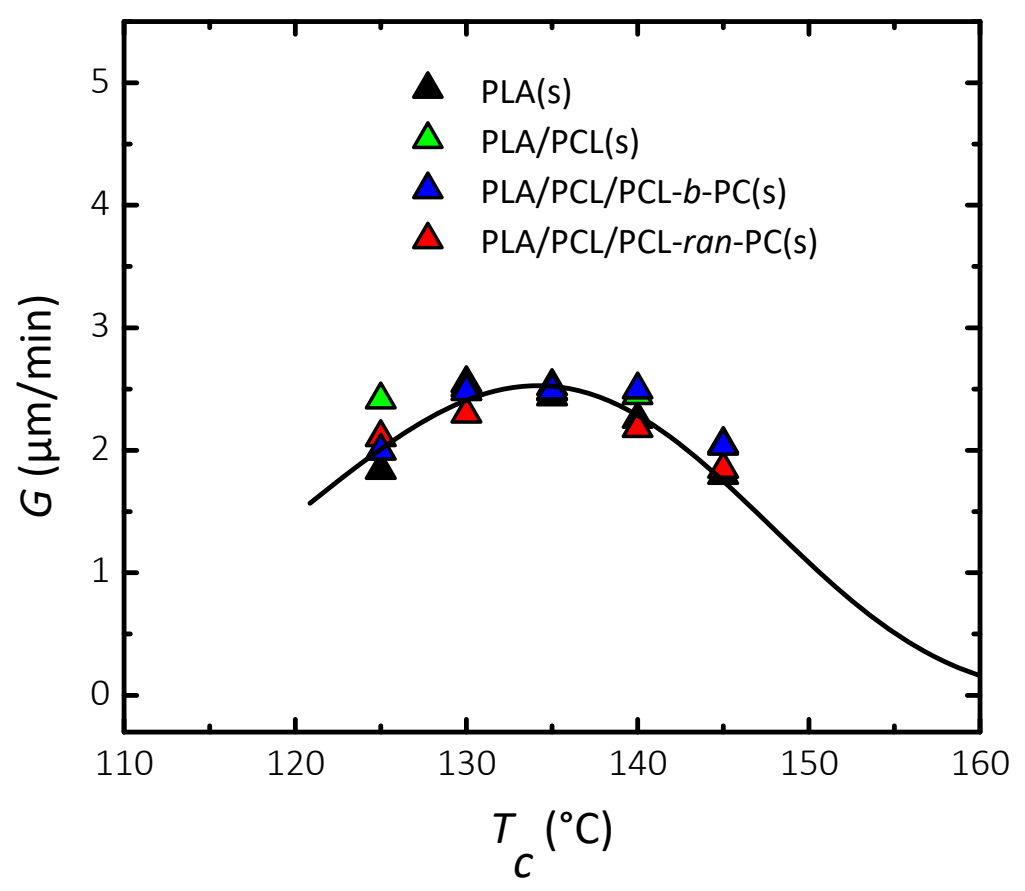

This item was downloaded from IRIS Università di Bologna (https://cris.unibo.it/) 
Figure 10. Spherulitic growth rate $G$ as a function of isothermal crystallization temperature $T_{c}$ for neat PLA and PLA phase within PLA/PCL and PLA/PCL/PCL-Co-PC solvent mixed blends. The solid line represents an arbitrary fit to guide the eye.

\subsubsection{Isothermal overall crystallization of PLA phase}

The inverse of the half-crystallization time, determined by isothermal crystallization from the melt employing DSC, provides an experimental measure of the overall crystallization rate, which includes both nucleation and spherulitic growth.

Figure 11 shows plots of the overall crystallization rate (expressed as the inverse of halfcrystallization time) as a function of temperature for melt blended samples, while in Figure 12 the plots are reported for the corresponding solution mixed samples.

The solid lines correspond to arbitrary fits performed to guide the eye. All the samples display the typical bell-shape trend, where the crystallization rate goes through a maximum as the kinetics changes from nucleation control at higher temperatures to diffusion control at lower temperatures.

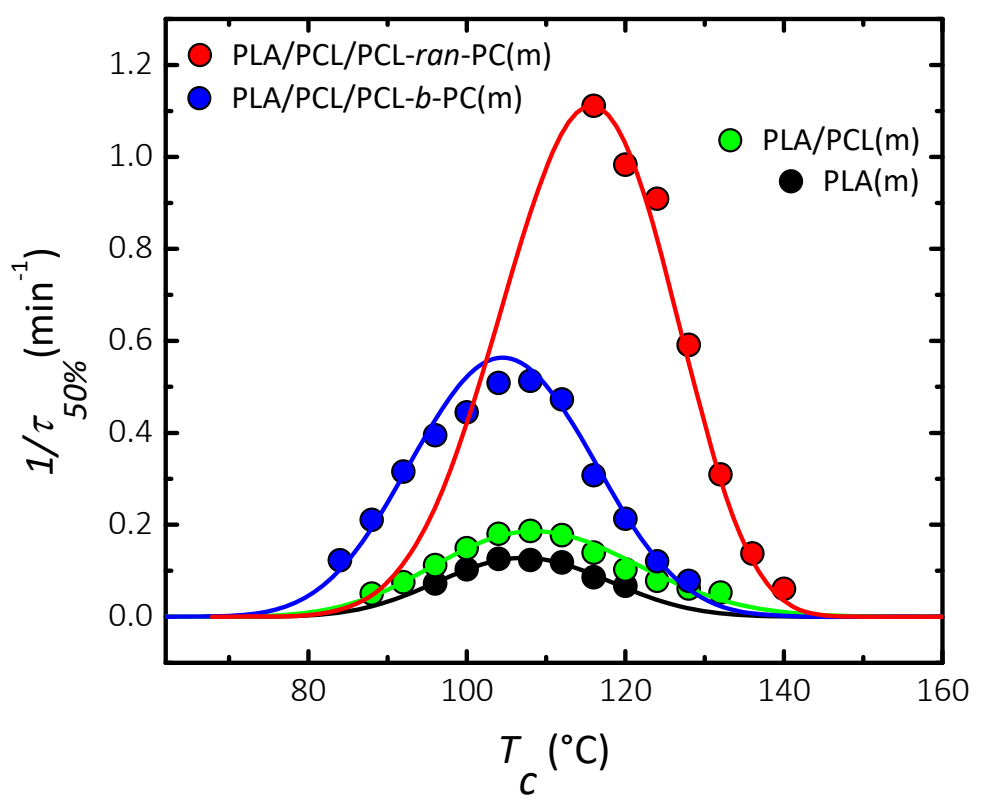

Figure 11. Isothermal crystallization experiments from the melt state. Overall crystallization rate $\left(1 / \tau_{50 \%}\right)$ as a function of isothermal crystallization temperature Tc in neat PLA and PLA phase within PLA/PCL and $P L A / P C L / P C L-c o-P C$ melt mixed blends. The solid lines represent arbitrary fits to guide the eye.

This item was downloaded from IRIS Università di Bologna (https://cris.unibo.it/)

When citing, please refer to the published version. 
The crystallization rate of neat PLA does not change upon different processing conditions. Both neat PLA samples, obtained by melt (Figure 11) and solution (Figure 12) processing as well, achieve their maximum relative crystallinity in 16 minutes at $T_{c}=104{ }^{\circ} \mathrm{C}$, where the overall crystallization rate goes through a maximum. This result is consistent with the non-isothermal DSC cooling experiments, in which no crystallization of PLA was detected during cooling, for both melt and solution processing samples, as the cooling rate $\left(10^{\circ} \mathrm{C} / \mathrm{min}\right)$ was too fast for crystallization to occur.

At the same time, the effect of PCL addition on the PLA phase crystallization rate is very similar for both melt and solution mixed samples. PLA/PCL(m) blend shows its maximum crystallization rate at $T_{c}=108{ }^{\circ} \mathrm{C}$ and completes its crystallization after 10.8 minutes (Figure 11), while PLA/PCL(s) achieves its maximum relative crystallinity after 12 minutes at the same temperature (Figure 12).

Instead, upon the addition of PC-co-PCL based copolymers, the crystallization rate of PLA phase changes following the different processing condition (i.e., melt (Figure 11) or solution (Figure 12) blending).

This item was downloaded from IRIS Università di Bologna (https://cris.unibo.it/) 


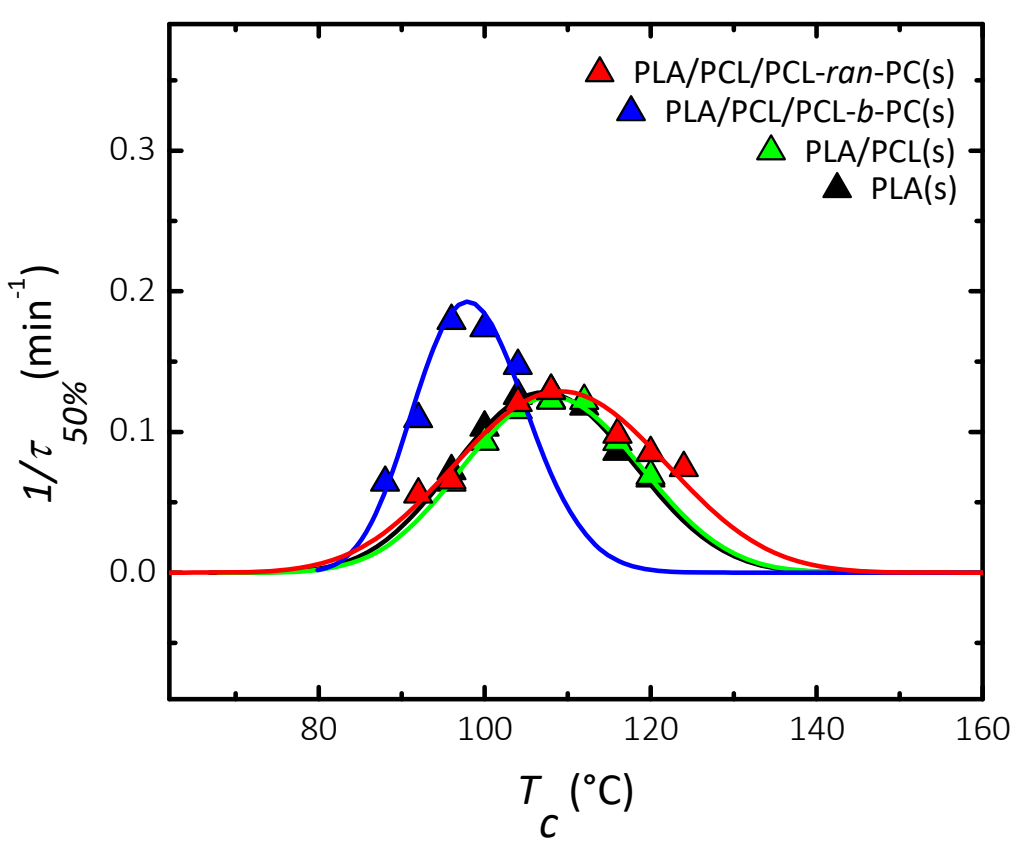

Figure 12. Isothermal crystallization experiments from the melt state. Overall crystallization rate $\left(1 / \tau_{50 \%}\right)$ as a function of isothermal crystallization temperature Tc in neat PLA and PLA phase within PLA/PCL and PLA/PCL/PCL-co-PC solution mixed blends. The solid lines represent arbitrary fits to guide the eye.

As Figure 11 reports, PC-co-PCL based copolymers addition to melt mixed blends causes an enhancement of the crystallization rate due to the molecular weight reduction induced by the copolymers. Taking neat PLA(m) as reference material, PLA/PCL/PCL- $b$-PC(m) shows a threefold increase, while in PLA/PCL/PCL-ran-PC(m) the crystallization rate is enhanced ten times. We can compare these results with Figure 7 and Figure 9. Figure 7 indicates that copolymer addition increases the nucleation density with respect to the neat blend (see Figures $7 b, 7 c$ and $7 d$ ). On the other hand, Figure 9 also reports an increase in spherulitic growth rate with copolymer addition (which is larger for the random copolymer case). Therefore, the results of Figure 11 that report overall crystallization rate (which include both nucleation and spherulitic growth) are consistent and reflect the degradation of PLA chains during melt blending.

This item was downloaded from IRIS Università di Bologna (https://cris.unibo.it/)

When citing, please refer to the published version. 
On the other hand, adding PC-ran-PCL copolymers to solution mixed samples causes insignificant changes to PLA crystallization rate. Figure 12 shows that the only sample showing some small difference in comparison to PLA(s) is PLA/PCL/PCL- $b-\mathrm{PC}(\mathrm{s})$, where the kinetics accelerates in the maximum of the curve from 11 to $15 \mathrm{~min}$. A difference much smaller to those obtained in Figure 11 for melt processed blends.

As it was already detected, the differences of overall crystallization kinetics must be due to the different molecular weights of PLA chains. Such molecular weight reduction, enhances both nucleation (Figure 7) and growth rates (Figure 9).

Our results are consistent with a previous study of Santonja-Blasco et al. [41] where they studied the crystallization kinetics of polylactide before and after being degraded by thermal, biological, and photoirradiation means. The results obtained indicated that $T_{c}$ and $T_{m}$ values were insensitive to changes in the weight average molecular weight of the samples in the range between $40-220 \mathrm{~kg} / \mathrm{mol}$. On the other hand, the spherulitic growth rate data was very sensitive to degradation. No measurements of overall crystallization kinetics were reported.

\section{Conclusions}

The addition of low molecular weight PCL-co-PC copolymers to PLA/PCL blends has induced degradation reactions during melt blending that have reduced the molecular weight of the PLA component in the blends. Such molecular weight reduction increases both nucleation and growth rates of PLA. However, when the same blends are prepared by solution mixing, no degradation could be detected.

The measurement of spherulitic growth kinetics for the PLA component in the blends or the measurement of the overall crystallization kinetics by DSC is a very sensitive tool to detect degradation of PLA. The reason for this sensitivity is related to the increased chain diffusion, which

This item was downloaded from IRIS Università di Bologna (https://cris.unibo.it/)

When citing, please refer to the published version. 
improves the ability of PLA to crystallize and in particular, accelerates its spherulitic growth. In this work, the degradation of PLA chains does not influence $T_{m}$ values (as the range of PLA weight average molecular weights involved is always in the region where $T_{m}$ values do not vary with molecular weight, i.e., above approximately $60 \mathrm{~kg} / \mathrm{mol}$ ). Therefore, degradation cannot be detected by DSC measurements. However, the spherulitic or overall crystallization kinetics can be employed as sensitive tools to detect very large differences in crystallization rates (up to ten times in the more extreme cases) that are a consequence of degradation.

\section{Acknowledgments}

The authors acknowledge the financial support from the Italian national PRIN research program 2010-2011. The POLYMAT/ UPV/EHU team would like to acknowledge funding from the following projects: GIC IT-1309-19 (Basque Government) and Mineco MAT2017-83014-C2-1-P. Discussions with Prof. Rufina Alamo are gratefully acknowledged.

\section{References}

[1] J.M. Raquez, Y. Habibi, M. Murariu, P. Dubois, Polylactide (PLA)-based nanocomposites, Prog. Polym. Sci., 38 (10-11) (2013), pp. 1504-1542.

[2] R.M. Rasala, A.V. Janorkar, D.E. Hirt, Poly(lactic acid modifications), Prog. Polym. Sci. 35 (2010), pp. 338-356.

[3] J.J. Kolstad, Crystallization kinetics of poly(L-lactide-co-meso-lactide), J. Appl. Polym. Sci., 62 (1996), pp. 1079-1091.

[4] J. M. Ferri, O. Fenollar, A. Jorda-Vilaplana, D. Garcia-Sanoguera, R. Balart, Effect of miscibility on mechanical and thermal properties of poly(lactic acid)/polycaprolactone blends, Polym. Int., 65 (2016), pp. 453-463.

[5] D. David, T. Sincock, Estimation of miscibility of polymer blends using the solubility parameter concept, Polymer, 33 (1992), pp. 4505-4514.

[6] L. A. Utracki, in Polymer Blends Handbook, ed. L. A. Utracki, Springer Netherlands, 2003, ch. 2, pp. 123-201.

This item was downloaded from IRIS Università di Bologna (https://cris.unibo.it/)

When citing, please refer to the published version. 
[7] A. J. Müller and R. M. Michell, Polymer Morphology: Principles, Characterization, and Processing, ed. Q. Guo, John Wiley \& Sons, Hoboken, NJ, USA, 2016, pp. 72-99.

[8] T. Patrício, P. Bártolo, Thermal stability of PCL/PLA blends produced by physical blending process, Procedia Eng., 59 (2013), pp. 292-297.

[9] T. Patrício, M. Domingos, A. Gloria, P. Bártolo, Characterisation of PCL and PCL/PLA scaffolds for tissue engineering, Procedia CIRP, 5 (2013), pp. 110-114.

[10]Y. Y. Chen, L. M. Geever, C. L. Higginbotham, D. M. Devine, Analysis of the mechanical properties of solvent cast blends of PLA/PCL, Eng. Technol. Res., 679 (2014), pp. 50-56.

[11] M. E. Broz, D. L. VanderHart, N. R. Washburn. Structure and mechanical properties of poly(D,L-Lactic Acid)/poly(ع-Caprolactone), Biomaterials, 24(23) (2003), pp. 4181-4190.

[12] I. Fortelný, A. Ostafińska, D. Michálková, J. Jůza, J. Mikešová, M. Šlouf, Phase structure evolution during mixing and processing of poly(lactic acid)/polycaprolactone (PLA/PCL) blends, Polym. Bull., 72(11) (2015), pp. 2931-2947.

[13]C. L Simões, J. C. Viana, A. M. Cunha. Mechanical properties of poly(e-caprolactone) and poly(lactic acid) blends, J. Appl. Polym. Sci., 112(1) (2009), pp. 345-352.

[14]J. Urquijo , G. Guerrica-Echevarría, J. I. Eguiazabal. Melt processed PLA/PCL blends. Effect of processing method on phase structure, morphology, and mechanical properties, J. Appl. Polym. Sci., 42641 (2015).

[15] D. Koning, J. Pagnoulle, Strategies for compatibilization of polymer blends, Prog. Polym. Sci., 23(97) (1998), pp. 707-757.

[16]J-B Zeng, K-A Li, K-A Du, Compatibilization strategies in poly(lactic acid)-based blends, RSC Adv., 5(41) (2015), pp. 32546-32565.

[17]D. Wu, Y. Zhang, L. Yuan, M. Zhang, W. Zhou. Viscoelastic interfacial properties of compatibilized poly(e-caprolactone)/polylactide blend, J. Polym. Sci. Part B Polym. Phys., 48(7) (2010), pp. 756-765.

[18] M. Rizzuto, L. Marinetti, D. Caretti, A. Mugica, M. Zubitur, AJ Müller. Can Poly( $\varepsilon-$ Caprolactone) crystals nucleate glassy Polylactide? CrystEngComm, 19 (2017), pp. 3178-3191.

[19]N-S Choi, C-H Kim, KY Cho, J-K Park. Morphology and hydrolysis of PCL/PLLA blends

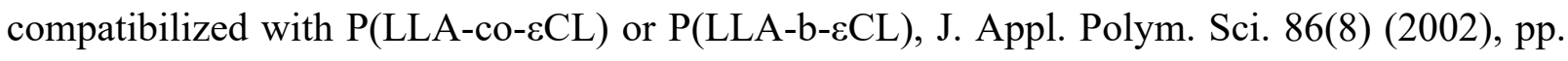
1892-1898.

[20] S. Xiang, L. Feng, X. Bian, B. Zhang, B. Sun, Y. Liu, G. Li, X. Chen. Toughening modification

This item was downloaded from IRIS Università di Bologna (https://cris.unibo.it/)

When citing, please refer to the published version. 
of PLLA with PCL in the presence of PCL-b-PLLA diblock copolymers as compatibilized, Polym. Adv. Technol., (2019), pp. 1-10.

[21]A. Golovoy, M. F. Cheung, K. R. Carduner, M. J. Rokosz. Control of transesterification in polyester blends, Polym. Eng. Sci., 29(18) (1989), pp. 1226-1231.

[22] V. Taubner, R. Shishoo. Influence of processing parameters on the degradation of poly(L-lactide) during extrusion, J. Appl. Polym. Sci. 79 (12) (2001), pp. 2128-2135

[23] M. L. Arnal, M. E. Matos, R. A. Morales, O. O. Santana, A. J. Müller, Evaluation of the fractionated crystallization of dispersed polyolefins in a polystyrene matrix. Macromol. Chem. Phys., 199 (1998), pp. 2275-2298.

[24]A. T. Lorenzo, M. L. Arnal, J. Albuerne, A. J. Müller. DSC isothermal polymer crystallization kinetics measurements and the use of the Avrami equation to fit the data: Guidelines to avoid common problems, Polym. Test., 26 (2007), pp. 222-231.

[25]M. M. Coleman, C. J. Serman, D. E. Bhagwagar, P. C. Painter, A practical guide to polymer miscibility, Polymer, 31(7) (1990), pp. 1187-1203.

[26] A. J. Müller, V. Balsamo, M. L. Arnal, T. Jakob, H. Schmalz, V. Abetz, Homogeneous nucleation and fractionated crystallization in block copolymers, Macromolecules, 35(8) (2002), pp. 3048-3058.

[27] I. Navarro-Baena, V. Sessini, F. Dominici, L. Torre, J.M. Kenny, L. Peponi. Thermally-activated shape memory behaviour of bionanocomposites reinforced with cellulose nanocrystals, Polym. Degrad. Stab., 132 (2016), pp. 97-108.

[28] F. Carrasco, P. Pagès, J. Gàmez-Pérez, O. O. Santana, M. L. Maspoch, Processing of poly(lactic acid). Characterization of chemical structure, thermal stability and mechanical properties, Polym. Degrad. Stab., 95(2) (2010), pp. 116-125.

[29] V. Balsamo, N. Calzadilla, G. Mora, A.J. Müller. Thermal characterization of polycarbonate/polycaprolactone blends, Journal of Polymer Science Part B: Polymer Physics, 39 (2001), pp. 771-785.

[30] A. J. Müller; V. Balsamo, M.L. Arnal. Nucleation and crystallization in diblock and triblock copolymers. Advances in Polymer Science, 190 (2005) 1-63.

[31] RM Michell, I. Blaszczyk-Lezak, C. Mijangos, A. J. Müller. Confinement effects on polymer crystallization: From droplets to alumina nanopores, Polymer, 54 (2013, pp.) 4059-4077.

This item was downloaded from IRIS Università di Bologna (https://cris.unibo.it/)

When citing, please refer to the published version. 
[32] R. M. Michell, A. J. Müller. Confined Crystallization of Polymeric Materials, Prog. Polym. Sci., 54-55 (2016), pp. 183-213.

[33] M. Pracella, in Handbook of Polymer Crystallization, ed. G. C. R. E. Piorkowska, John Wiley \& Sons, Hoboken, NJ, USA, 2013, pp. 287-326.

[34] A. J. Müller, M. Avila, G. Saenz, J. Salazar, in Poly(lactic acid) Science and Technology: Processing, Properties, Additives and Applications, The Royal Society of Chemistry, 2015, pp. 66-98.

[35] T. Kawai, N. Rahman, G. Matsuba, K. Nishida, T. Kanaya, M. Nakano, H. Okamoto, J. Kawada, A. Usuki, N. Honma, K. Nakajima, M. Matsuda, Crystallization and melting behavior of poly (L-lactic acid), Macromolecules 40(26) (2007), pp. 9463-9469.

[36] Z. Wei, P. Song, C. Zhou, G. Chen, Y. Chang, J. Li, W. Zhang, J. Liang, Insight into the annealing peak and microstructural changes of poly(l-lactic acid) by annealing at elevated temperatures, Polymer 44 (2003), pp. 711-717.

[37] J. R. Sarasua, R.E Prud'homme, W Wisniewski, A. Le Borgne, N. Spassky, Crystallization and Melting Behavior of Polylactides, Macromolecules, 31(12) (1998), pp. 3845-3905.

[38] B. Crist, JM. Schultz. Polymer spherulites: A critical review, Prog. Polym. Sci., 5 (2016), pp. 163.

[39] J. M. Schultz. Polymer Materials Science. Prentice Hall, Inc. New Jersey 1974.

[40] P. Pan, W. Kai, B. Zhu, T. Dong, Y Inoue, Polymorphous crystallization and multiple melting behavior of poly(L-lactide): molecular weight dependence. Macromolecules, 40 (2007), pp. 6898-6905.

[41] L. Santonja-Blasco, A. Ribes-Greus, R. G. Alamo, Comparative thermal, biological and photodegradation kinetics of polylactide and effect on crystallization rates. Polym. Degrad. Stab., 98 (2013), pp. 771-784.

This item was downloaded from IRIS Università di Bologna (https://cris.unibo.it/)

When citing, please refer to the published version. 